\title{
4
}

\section{In Vivo and In Vitro Models to Study Amyotrophic Lateral Sclerosis}

\author{
François Berthod and François Gros-Louis \\ Centre LOEX de l'Université Laval, \\ Centre de recherche FRSQ du Centre hospitalier affilié universitaire de Québec, \\ Département de Chirurgie, Faculté de Médecine, Université Laval, Québec, \\ Canada
}

\section{Introduction}

Amyotrophic Lateral Sclerosis (ALS) is the most common adult-onset neurodegenerative disorder characterized by the death of large motor neurons in the cerebral cortex and spinal cord (Tandan and Bradley, 1985). Dysfunction and death of these cell populations lead to progressive muscle weakness, atrophy, fasciculations, spasticity and ultimately, paralysis and death usually within 3 to 5 years after disease onset (Mulder, 1982). The estimated worldwide incidence for this disease is around 2 per 100,000 in the general population and the life-long risk to develop ALS is approximately 1:2000. The disease occurs in sporadic $(90 \%)$ and familial forms (10\%) (Gros-Louis, et al., 2006). With the exception of few FALS cases in which other neurodegenerative disorders can simultaneously occur, FALS and SALS are clinically indistinguishable. To date, mutations in the $\mathrm{Cu} / \mathrm{Zn}$ superoxide dismutase 1 (SOD1) gene have remained the major known genetic causes associated with ALS. However, the mechanism whereby mutant SOD1 causes specific degeneration of motor neurons remains unclear. Nonetheless, many neuronal death pathways have been revealed through studies with transgenic mice expressing SOD1 mutants. Other vertebrate, invertebrate and in vitro models of ALS have also been described. Here, we will review various animal and cellular models that have been used to study the toxicity of ALS-linked gene mutations and also to investigate pathological hallmarks of the disease.

\subsection{Familial ALS}

Though most cases of ALS are sporadic, $10 \%$ of cases have affected relatives, some with clear Mendelian inheritance and high penetrance (Gros-Louis, et al., 2006). The landmark discovery in 1993 of missense mutations in the SOD1 gene in subsets of familial cases directed most ALS research to elucidate the mechanism of SOD1-mediadted disease (Rosen, et al., 1993). More recently, mutations in two other genes, TARDBP and FUS/TLS have been found in ALS patients (Kabashi, et al., 2008; Sreedharan, et al., 2008; Vance, et al., 2009). Rare mutations in other genes such as ANG, ALS2, DCTN1, MAPT, SETX and VAPB have also been described (for reviews see (Gros-Louis, et al., 2006)). Various other genetic mutations in the ELP3 ((Simpson, et al., 2009), FIG4 (Chow, et al., 2009), DAO (Mitchell, et al., 2010), OPTN (Maruyama, et al., 2010) and CHGB (Gros-Louis, et al., 2009a) genes have also been 
associated with the disease through several candidate gene-based association studies. Given the high degree of genetic and clinical heterogeneity seen in ALS patients, along with population-specific genetic risk factors for ALS, independent replication of these genetic association studies would be crucial in order to better understand the different mechanisms involved in these disease. As there are several excellent reviews in the literature describing these genes and their relevance to ALS, we will mainly describe the most recent and exciting advances involving SOD1, TARDBP and FUS in this area.

To date, family-based linkage studies and positional cloning have led to the identification of fifteen ALS-associated genes in which mutations have been identified in familial ALS cases (Table 1). Different research groups or consortiums have replicated these results in several populations. To date, a number of genes have been discovered as causative for the classical adult onset form of familial ALS with typical symptoms, namely SOD1, TARDBP, FUS/TLS, and C9ORF72 (DeJesus-Hernandez, et al., 2011; Kabashi, et al., 2008; Kwiatkowski, et al., 2009; Renton, et al., 2011; Rosen, et al., 1993; Sreedharan, et al., 2008). These genes cumulatively account for about $25 \%$ of familial cases, indicating that other causative genes remain to be identified. The difficulties to identify gene responsible for FALS arise in part because large families with sufficient statistical power for linkage analysis are hard to come by, due to the late-onset and age-dependant penetrance of the disease, and the relative short survival time of affected ALS patients. Furthermore, the high degree of genetic heterogeneity, i.e. many rare variants in many different genes individually having a modest effect on the total number of ALS cases, is also certainly a limiting factor for the identification of causative ALS-predisposing genes. Four other genes, namely DAO, OPTN, $A T A X 2$ and $V C P$ have also been included in this category, but the evidence for their role in predisposing to classical ALS needs to be confirmed in replication studies, and more families linked to these genes also need to be described (Elden, et al., 2010; Johnson, et al., 2010; Maruyama, et al., 2010; Mitchell, et al., 2010).

\begin{tabular}{|c|c|c|c|c|}
\hline FALS-associated known genes (gene symbol) & Inheritance & Onset & Mutation types & References \\
\hline Superoxyde dismutase 1 (SOD1) & $A D$ & Adult & Missense and truncation mutation & Rosen et al., 1993 \\
\hline TAR DNA-binding protein (TARDBP) & $A D$ & Adult & Missense and nonsense mutations & Kabashi et al., 2008; Sreedharan et al., 2008 \\
\hline Fused in sarcoma/translated in liposarcoma (FUS/T) & $A D$ and $A R$ & Adult & Missense mutations, indels & Kwiatkowski et al., 2009; Vance et al., 2009 \\
\hline Chromosome 9 opend reading frame 72 (C9ORF72, & $A D$ & Adult 1 & texanucleotide GGGGCC expansion repe & inton et al., 2011, DeJesus-Hernandez et al., 201 \\
\hline Ataxin 2 (ATAX2) & $A D$ & Adult & Trinucleotide CAG expansion repeat & Elden et al., 2010 \\
\hline Ubiquitin-like protein ubiquilin2 (UBQLN2) & X-linked & Adult & Missense mutations & Deng et al., 2011 \\
\hline Optineurin (OPTN) & $A D$ & Adult & Missense and nonsense mutations & Maruyama et al., 2010 \\
\hline$D$-amino acid oxidase $(D A O)$ & $A D$ & Adult & One R199W missense mutation & Mitchell et al., 2010 \\
\hline Amyotrophic lateral sclerosis 2 (ALS2) & AR & Juvenile & Missense and nonsense mutations & Hadano et al., 2002, Yang et al., 2002 \\
\hline Valosin-containing protein (VCP) & $A D$ & Adult & Missense mutations & Johnson et al., 2010 \\
\hline Vesicle-associated membrane protein B (VAPB) & $A D$ & Adult & Missense mutations & Nishimura et al., 2004 \\
\hline Microtubule-associated protein tau (MAPT) & $A D$ & Adult & Missense and 5'-splice-site mutations & Hutton et al., 1998 \\
\hline Dynactin 1 (DCTN1) & $A D$ & Adult & Missense mutations & Puls et al., 2003 \\
\hline Angiogenin & $A D$ & Adult & Missense mutations & Chen et al., 2004 \\
\hline Senataxin (SETX) & $A D$ & Juvenile & Missense mutations & Greeway et al., 2006 \\
\hline
\end{tabular}

Table 1. Identified genes predisposing for familial ALS and/or ALS-FTLD

FALS: Familial ALS, ALS-FTLD: ALS with frontotemporal lobar degeneration,

AD: autosomal dominant, AR: autosomal recessive, Indels: insertions, deletions

The identification of other genes responsible for the disease and the understanding of the molecular pathways involved will bring some new insights into the mechanisms of disease pathogenesis, and may also elucidate the underlying mechanism(s) for specific motor neuron degeneration observed in ALS. 


\subsection{Sporadic ALS}

For most cases of ALS, the causes are unknown. A genetic component is also thought to contribute to the pathogenesis of sporadic ALS, which accounts for the majority of ALS cases. However, identification of gene mutations associated with SALS has met with limited success so far. Several groups have reported on gene variants and association studies found in individuals with sporadic ALS, each accounting for a small number of the total cases reflecting a complex pattern of inheritance with very low penetrance, a high degree of heterogeneity and/or the existence of environmental factors predisposing to ALS. Because familial and sporadic forms of the disease are clinically and pathologically similar, understanding the familial form will shed light on possible epidemiological and pathophysiological mechanisms in SALS.

Many divergent data generated by different research groups who have studied different populations around the world have been published. The use of an adequate size population with appropriate control individuals is needed in order to reach enough statistical power and to observe any significant results. Homogeneity regarding ethnical origin, age, age of onset, disease duration, site of the first symptoms and gender among the studied populations is essential to design a good and robust genetic study. The requirement for larger sample sizes and possibly more sensitive and efficient analytic tools allowing for reliable detection across studied populations are now becoming more and more available as non cost-effective genotyping strategies are being developed.

The identifications of different genes and genetic risk factors associated with ALS over the past years have highlighted common molecular pathways mainly involving intracellular cell trafficking and RNA metabolism. To what extent these pathways are implicated in ALS remain to be determined and studied further. However, it is interesting to note that genes such as ALS2, VAPB, MAPT, DCTN1, EAAT2, NEFH, PRPH, FIG4, CNTF, CHGB and OPTN in which mutations have been found in a subset of FALS and/or SALS patients, are all related to intracellular trafficking either via axonal transport, vesicle docking and transport, or microtubule and neurofilament stabilization. Furthermore, this common theme is also seen in other motor neuron diseases and neurodegenerative disorders such as hereditary spastic paraplegia, Parkinson's disease, spinal muscular atrophy and Charcot-Marie-tooth disease. It is also noteworthy that RNA metabolism via alternative splicing abnormalities or RNA binding is also a common theme observed amongst the different ALS related genes such as ALS2, MAPT, EAAT2, PRPH, GluR2, CNTF, SETX, SMN1, SMN2, TARDBP and FUS/TLS. The high degree of genetic heterogeneity observed in ALS suggests that an individual phenotype could result from the sum of several contributing gene defects and/or epigenetic influences, which individually do not cause disease, and may explain the difficulties in identifying genes associated with SALS. The identification of other genes associated with motor neuron disease, as well as the determination of genetic and/or environmental factors that predispose to SALS is crucial in the development of novel therapies for ALS. The generation of cellular or animal models to study SALS, in which the disease can be closely replicated, would also be the utmost importance to reach a full understanding of the molecular mechanisms and environmental factors associated with SALS.

\subsection{ALS with cognitive impairments}

In recent years, key developments have revealed a novel neurodegenerative disease spectrum with clinical symptoms overlapping between ALS and frontotemporal lobar 
degeneration (FTLD) (Strong and Yang, 2011). Cognitive and behavioral impairment is well described in ALS with a significant proportion of patients meeting strict diagnostic criteria for FTLD. Neuroimaging and pathological studies have shown clear involvement of nonmotor areas of the brain. More recently, distinct subtypes of frontotemporal lobar dysfunction have been identified in ALS and further work to distinguish these phenotypes and their correlate neuropathology is under way. Attention has been devoted lately to a gene coding for a DNA/RNA binding protein, which have been implicated in the pathogenesis of ALS with cognitive impairments. Indeed, dominant mutations in the TARDBP gene, encoding for TDP-43, were reported by several groups as a primary cause of ALS in about 3\% familial cases and 1.5\% sporadic cases (Chio, et al., 2011; Corrado, et al., 2009; Daoud, et al., 2009; Gitcho, et al., 2008; Kabashi, et al., 2008; Millecamps, et al., 2010; Sreedharan, et al., 2008; Van Deerlin, et al., 2008). The discovery of gene mutations linked to human ALS has provided plethora opportunities to develop model systems for investigating mechanisms of TDP-43 associated disease.

Motor neuron degeneration can also occasionally occurs in patients with Parkinson's disease and frontotemporal dementia (FTD). This disease is also called Disinhibition-dementiaparkinsonism-amyotrophy complex (DDPAC) or FTDP17 (Lynch, et al., 1994). The pathologic features distinguish this disease from the ALS-parkinsonism-dementia complex of Guam seen in the peninsula of Japan and from ALS-FTD linked to chromosome 9. Mutations in the microtubule-associated protein tau gene (MAPT) have been shown to be associated with FTD and Parkinsonism (Hutton, et al., 1998). Tau is a member of the microtubule-associated protein family, which have the principal function stabilizing microtubules and promoting their assembly by binding to tubulin. As a number of reviews (Gros-Louis, et al., 2006; Julien and Kriz, 2006) have already described the relationship between MAPT and ALS, the following sections will not discuss in details about this gene and FTDP17 models that have been generated.

\section{In vivo models to study ALS}

The exact mechanisms by which all the above-described gene products are involved in ALS pathogenesis are the subject of many ongoing researches. Current thinking about ALS pathogenesis revolves around the interplay between pre-existing genetic susceptibility and environmental factors that may trigger disease. The search for putative environmental factors has remained elusive however; transgenic animal studies have yielded the greatest wealth of information to date. Through these studies, multiple cellular pathways have been identified including, protein misfolding, RNA processing, oxidative stress, excitotoxicity, axonal transport, mitochondrial dysfunction and abnormal secretion of proteins. Nevertheless, how accurately these animal models replicate all ALS clinical symptoms of the human illness remains an unanswered and troublesome question. This section will include the complete description of all published invertebrate and vertebrate models of ALS. Other considerations such as advantages, disadvantages, cost and availability of each model will also be discussed. Each model organism has its own advantages and disadvantages. Choosing an appropriate model depends on the question being asked. Many laboratories find it useful to perform parallel experiments in two or more model systems to understand different aspects of a biochemical process. 


\subsection{Invertebrate models}

Invertebrate model organisms include systems such as the simple yeast (fungi), fly, and nematode. The study of these experimental systems began with genetics and development, moved into molecular and cellular biology prior to most recently propelled into functional genomics and proteomics. These model organisms have highly manipulable genomes allowing for rapid generation of transgenic lines to provide insight on gene functions and protein network interactions. In 2002, Sydner Brenner, Robert Horvitz and John Sulston received the Nobel Prize in Physiology and Medicine for their establishment of the nematode Caenorhadditis elegans as a novel model organism to explore the molecular bases of organ development and cell death. Their discoveries identified key genes involved in cell division, differentiation and apoptosis. They determined that these genes were in fact highly conserved both structurally and functionally with higher organisms, including humans. Their studies provided the framework in which simpler organisms can be used to define key pathways and processes of relevance with the important benefit that the results are often directly applicable to understand human diseases.

The key points into generating models for human disease using smaller invertebrate organisms should encompass high degree of conservation with mammals in order for the model to be useful for the identification of the molecular components implicated in disease pathogenesis. A fully sequenced genome of the studied organism should ideally be also easily accessible for genome comparison with higher vertebrates and mammals in order to facilitate evolutionary genomics studies and to quickly generate transgenic animals through DNA transformation. The model organism should also provide significant experimental advantages over their mammalian counterparts, including a short generation time, small size, ease and reasonable cost of maintenance. It should be also amenable to both forward (phenotype to gene) and reverse (gene to phenotype) genetic approaches, which are essential molecular tools to dissect out and understand gene function. Classic forward genetic characteristics allow for the identification of novel molecules or pathways involved in a particular cellular process. This can be one of the most powerful attributes of invertebrate models. Forward-genetic screens using chemical mutagens are one of the most universal ways to generate mutants to elucidate gene function. On the other side, reverse genetics allows the quick identification of pathways on which a particular gene acts. Genetic knockdown mutants, using RNA interference (RNAi) technology in which a gene product is dramatically reduced by introducing double-stranded RNA (dsRNA) into the organism, can also provide invaluable information on the role a gene plays in a biological process.

The obvious disadvantage of using invertebrate model organisms such as fly or worm models is that there are evolutionarily far from mammals and that many physiological functions are not conserved, e.g. the immune system. Furthermore, their organs are extremely undeveloped and simple compared to other animals. The limited cellular diversity also represents a major disadvantage.

\subsubsection{Caenorhabditis elegans}

Yet, for the vast majority of neurodegenerative disorders including ALS, the mechanisms underlying neuronal dysfunction and death remain poorly understood despite the identification of relevant disease genes. Given the fact that molecular conservation in neuronal signaling pathways across vertebrate and invertebrate is relatively high and since the Caenorhabditis elegans nervous system contains almost all of the known signaling and 
neurotransmitter systems found in mammals (Bargmann, 1998), many researchers have turned to this model organism to identify the mechanisms underlying neurodegenerative disease pathology.

Research in C. elegans has been instrumental, especially over the last decade, for the elucidation of molecular pathways implicated in many human diseases. This is highly related to the fact that the $C$. elegans genome was the first multicellular organism to be completely sequenced in 1998 (Anonymous, 1998). The worm genome contains approximately 20,000 genes, compared with 25,000 in the human genome highlighting that C. elegans is a powerful model system for genetic analysis and for exploring the molecular mechanisms of neuron development, function, and disease. Furthermore, at least $42 \%$ of human disease related genes have a C. elegans ortholog, suggesting that most biochemical pathways are conserved across evolution (Culetto and Sattelle, 2000).

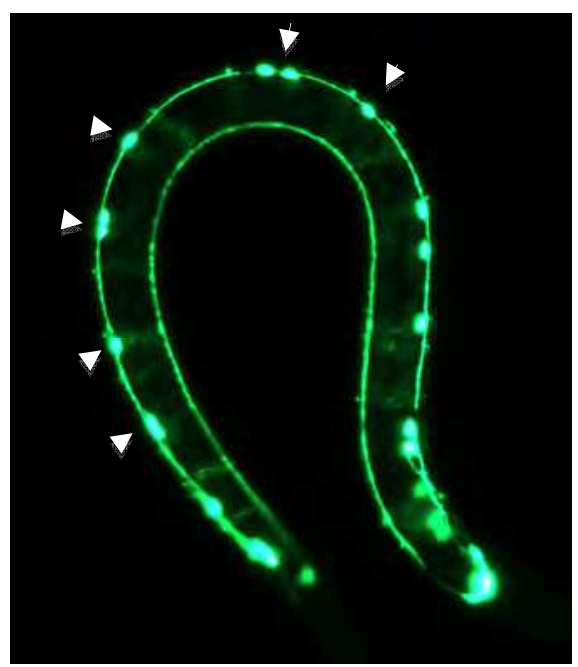

Fig. 1. Transgenic UNC-47:GFP C. elegans

In C. elegans, 26 neurons of 5 different classes express the neurotransmitter GammaAminobutyric Acid (GABA) (McIntire, et al., 1993). Nineteen of these GABAergic neurons, known as the type $\mathrm{D}$ neurons, are required for normal locomotion by providing dorsoventral cross-inhibition to body wall muscles (McIntire, et al., 1993; White, et al., 1986). Therefore, this transgenic worm would be a good model to depict pathological changes associated with locomotor dysfunction. Arrowheads point to type D neurons (only some of the D neurons are indicated). Courtesy of Dr Alex J. Parker from the Centre of Excellence in Neuromics, University of Montreal, Quebec, Canada.

C. elegans is a free-living nematode of about 1 millimeter in length with a short generation cycle ( 3 days) and lifespan (around 3 weeks), large brood size (approximately 300 progeny from a single hermaphrodite), and a transparent anatomically simple body that allows for the visualization of all cell types at all stages of development (Brenner, 1974). This last feature allows researchers to easily detect and quantify neuronal cell death and protein inclusions using optical techniques. The complete C. elegans embryonic cell-lineage is also known, making it possible to follow organogenesis from the earliest stages of embryos 
formation to the terminal steps of differentiation and morphogenesis (Sulston, et al., 1983). Additionally, C. elegans have a simple nervous system of 302 neurons out of 959 cells in the adult hermaphrodite, in which each neuron has a unique position (Sulston, 1983). Twenty of these neurons are located inside the pharynx, which has its own nervous system. The remaining 282 neurons are located in various ganglia in the head and tail and also along the ventral cord, the main longitudinal axon tract (Fig. 1). The majority of the neurons develop during embryogenesis. However, 80 of them, mainly motor neurons, develop postembryonically. The structure of the nervous system is highly reproducible from animal to animal and has been described in detail by electron microscopic reconstruction (White, et al., 1986) This technique allowed White and colleague to obtain high-resolution images to identify all the synapses formed in C. elegans (about 5000 chemical synapses, 2000 neuromuscular junctions and some 500 gap junctions) and to map all the connections in order to work out the entire neuronal circuit of this model organism.

In addition, gene knockdown by RNA interference can be relatively easily achieved in most cell types in vivo or in vitro by injecting the double stranded RNA for a specific gene of interest, by simply soaking the animals in dsRNA, or by feeding the animals with bacteria expressing the desired dsRNA (Fire, et al., 1998; Maeda, et al., 2001). Primary neuronal and muscular cell cultures obtained by dissecting this animal have also been optimized to allow for stable growth of embryonic cells (Christensen, et al., 2002).

For all these reasons, C. elegans has emerged as an attractive and powerful in vivo model system for studying pathological mechanisms in several major neurodegenerative disorders, including ALS, providing clear leads towards the identification of potential targets for the development of new therapeutic interventions against human diseases.

\subsubsection{C. Elegans SOD1 models}

A number of $C$. elegans models have been developed that recapitulate many aspects of ALS pathogenesis. These transgenic models mainly expressed either the SOD1 or the TDP-43 protein under the control of various gene promoters. The first $C$. elegans ALS model was first generated in 2001 (Oeda, et al., 2001). This transgenic C. elagans model has been generated by introducing human wild type and various human FALS SOD1-linked mutations (A4V, G37R and G93A) under the control of hsp16-2 heat shock and myo-3 muscle-specific promoters. The heat inducible hsp16-2 promoter allows expression of mutant SOD1 in almost all tissues, including neurons, while the myo-3 muscle-specific promoter allows high level of protein expression in all of the muscle tissues except for the pharynx. Unfortunately, no morphological abnormalities and no discernable changes in survival or behavior were observed. However, the authors reported some interesting findings. The mutant SOD1 expressing nematodes showed a reduced resistance to paraquat-induced oxidative stress. Furthermore, oxidative stress significantly reduced the degradation rate of mutant SOD1 protein, and finally aberrant accumulation of mutant human SOD1 proteins was also observed when expressed in muscle cells. Interestingly, this later pathological phenotype is in line with the pathology observed in human post-mortem ALS tissues.

In a subsequent study, pan-neuronal expression of the G85R ALS-linked mutant form of human SOD1, using the C. elegans syntobrevin gene promoter (snb-1), coupled to a yellow fluorescent protein (YFP) produces strong locomotor defects and paralysis in this transgenic snb-1/G85RSOD1-YFP C. elegans model (Wang, et al., 2009a). Interestingly, the observed phenotype correlated with intra-neuronal SOD1 aggregation. Another SOD1 mutant $C$. elegans model in which aggregation, toxicity, and cellular interactions can be directly 
compared between different SOD1 mutants was also reported. This mutant SOD1-YFP model, expressing various SOD1 mutants (G85R, G93A, 127X) in C. elegans muscle cells by the use of the muscle specific unc-54 gene promoter resulted in mild cellular dysfunction (Gidalevitz, et al., 2009). However, when mutant SOD1 was introduced into genetic backgrounds harboring destabilizing temperature-sensitive mutations, the toxicity was enhanced significantly and a variety of toxic phenotypes were observed. Based on theses results, the authors concluded that the specific toxic phenotypes may not be simply due to aggregation toxicity of the causative mutant proteins, but may be modulated by the genetic interactions with cellular pathways harboring mildly destabilizing polymorphisms in the genetic background.

\subsubsection{C. Elegans TDP-43 models}

In order to study TDP-43 function and neurotoxicity, transgenic C. elegans model was generated allowing pan-neuronal expression of the wild-type TDP-43 human protein (Ash, et al., 2010). This was done using the $s n b-1$ gene promoter driving the expression of human TDP-43 cDNA in all neurons. The transgenic snb-1/hTDP-43 worms displayed a distinctive uncoordinated phenotype characterized by non-sinusoidal, slow movement and inappropriate responses to stimulus. Transgenic worms first display this phenotype during larval stages, and the phenotype remains constant throughout the adulthood. The authors have also found that this uncoordinated phenotype correlated with abnormal motor neuron synapses. The mechanism by which nuclear TDP-43 activity leads to abnormal synapses is still unknown, but the authors hypothesized that excessive TDP-43 activity may alters some component of RNA metabolism (e.g. alternative splicing), subsequently leading to altered production of specific proteins required for proper synaptic function. In another study, also describing a C. elegans model of TDP-43 proteinopathy, Liachko and colleagues similarly found that overexpression of normal human TDP-43 in all C. elegans neurons causes motor defects (Liachko, et al., 2010). However, they also found that overexpression of various human ALS-associated TDP-43 mutants (G290A, A315T, or M337V) cause a more severe motor dysfunction phenotype. Interestingly, the authors also demonstrated that the observed motor phenotype worsen over time and that the described mutant TDP-43 C. elegans model recapitulates some characteristic features seen in ALS and FTLD-U patients including progressive paralysis, reduced lifespan, and degeneration of motor neurons accompanied by hyperphosphorylation, truncation, and ubiquitination of the TDP-43 protein that accumulates in detergent insoluble protein deposits.

All the above described C. elegans models provide a good in vivo system to further dissect cellular and molecular mechanisms underlying disease. Further investigations using these models may reveal insights into SOD1 and TDP-43 functions, potentially reveal neurotoxic mechanisms relevant to ALS and other neurodegenerative diseases, and ultimately lead to the development of novel therapeutic targets.

\subsubsection{Drosophila melanogaster}

The fruit fly Drosophila melanogaster is a powerful genetic tool to study neurodegenerative diseases. Drosophila is a complex organism, with a functioning brain and nervous system, capable of many behaviors like learning, motility, and visual acuity. This model organism is one of the oldest multi cellular eukaryotic genetic models and has been used for almost a century to examine a variety of basic biological principles, including genetic inheritance, behavioral and developmental processes, and the first experimental description of the gene 
as a functional unit. Its importance for human health was recognized by the award of the Nobel Prize in Physiology and Medicine to Ed Lewis, Christiane Nusslein-Volhard and Eric Wieschaus in 1995 for their discoveries concerning the genetic control of early embryonic development using D. melanogaster as a model.
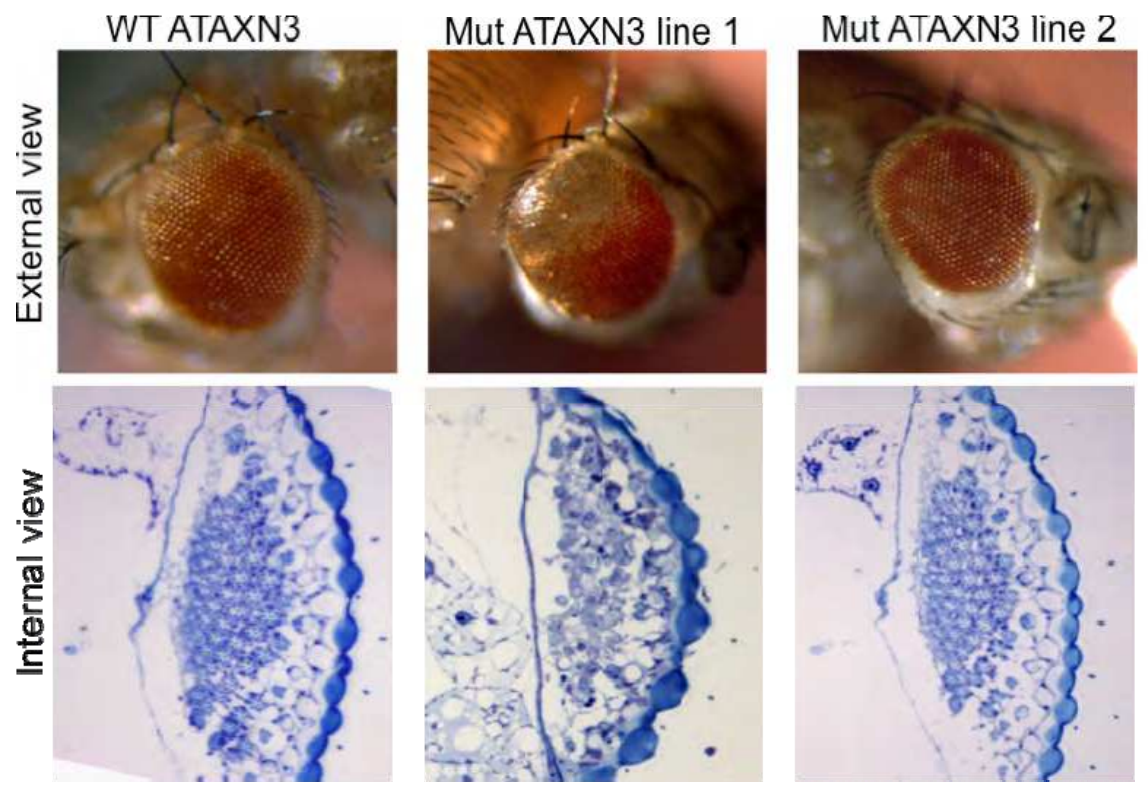

Fig. 2. Expression of human Ataxin3 gene in the compound eye of transgenic flies using the GAL4/UAS system.

Transgenic drosophila expressing human full-length WT or mutated Ataxin 3 (ATXN3) gene in the compound eye. Only mutant ATAXN3 flies showed an external and internal degeneration, which is characterized by cell death and irregular ommatidia and photoreceptor distribution. Courtesy of Dr Guy A. Rouleau from the Centre of Excellence in Neuromics, University of Montreal, Quebec, Canada.

Drosophila is cheap, of small size (approximately $2.5 \mathrm{~mm}$ ) and easy to maintain in the laboratory. One of the most attractive aspects of Drosophila for use as a model organism is its short reproductive cycle and large number of genetically identical progeny. Adult females can lay, following a circadian pattern, over 400 eggs within 10 days and their short 2-week generation time allows for quick analysis of mutant animals. The fly has only four pairs of chromosomes, including three autosomal chromosomes and one set of sexual $X / Y$ chromosomes which can be directly visualized in the giant polytene chromosome of the larval salivary gland. The Drosophila genome has been completely sequenced (Adams, et al., 2000). Its entire genome is encoded by roughly 13,600 genes as compared to 25,000 human genes. Another interesting feature of the fly is that it is relatively easy to drive time- and tissue-specific expression of any gene of interest using the yeast transcription activator protein Gal4 in combination with the Upstream Activation Sequence (UAS) to which Gal4 specifically binds to activate gene transcription (Brand and Perrimon, 1993). To study neurodegenerative diseases, the compound eye is predominantly used because it allows the 
generation of a neurodegenerative phenotype (rough eye phenotype) that can be easily appreciated under a standard light microscope (Fig. 2). In turn, the Gal4/UAS system can be also used to screen for genetic modifier (enhancer or suppressor) genes.

Based on these observations, it is obvious that Drosophila melanogaster can offer unique opportunities in the study of human neurodegeneration. Nonetheless, the major disadvantage of using D. melanogaster as a model is that forward genetic screen using RNA interference technology is more tedious than in the C.elegans model. For instance, at the moment, knockdown of genes by RNAi cannot be carried out by simply feeding flies with double-stranded RNA (as in the worm model); it has to be injected into the embryo. Although very laborious, this problem could be overcome by generating transgenic constructs expressing dsRNA for each transcript.

\subsubsection{Drosophila SOD1 models}

Initial ALS studies in Drosophila showed either reduced longevity and fertility, increased susceptibility to oxidative stress, motor deficits and/or necrotic cell death in the fly eye of Sod null flies (Phillips, et al., 1989). Surprisingly, subsequent studies in transgenic fly model, overexpressing human WT SOD1 only in motor neurons, showed an extension of lifespan, without affecting locomotion or motor neuron survival (Parkes, et al., 1998). In contrast, another study showed that selective expression of WT or human SOD1 (hSOD1) diseaselinked (A4V, G85R) mutants in motor neurons induced progressive motor dysfunctions, coupled with electrophysiological defects and abnormal accumulation of the protein and a stress response in surrounding glial cells (Watson, et al., 2008). These effects were accompanied by synaptic transmission deficits, focal accumulation of hSOD1 in motor neurons, and up-regulation of heat shock protein in glia. This work suggests that SOD can cause cell-autonomous damage to motor neurons, and highlights that motor neuron selective expression of hSOD1 can induces change in glial cells. These results are in line with findings that disease is not strictly autonomous to motor neurons and that toxicity can propagate from one cell to another (Boillee, et al., 2006; Clement, et al., 2003). Expression of a human SOD1 transgene in Drosophila motor neurons was achieved by using the yeast GAL4/UAS system. Interestingly, Mocket and colleagues showed that human WT SOD1 expression, placed in a Drosophila $\mathrm{Cu}-\mathrm{Zn}$ Sod null background, at very low levels was sufficient to rescue the life-span reduction, increased oxidative stress, and impaired physiological function associated with the Drosophila Sod null model described above (Mockett, et al., 2003). However, the introduction of FALS-linked SOD1 alleles (A4V, G37R, G41D, G93C, and I113T) only partly reversed these effects. These results, in conjunction with earlier findings from FALS SOD1 expression restricted to motor neurons, suggest that the introduction of FALS mutant SOD1 alleles in Drosophila does not result in a dominant gainof-function, as it is observed in human patients.

\subsubsection{Drosophila TDP-43 models}

A number of models for TDP-43 toxicity in flies have also been generated, revealing that the protein shows toxicity in vivo. Mainly, these independent studies have examined phenotypes associated with manipulation of both endogenous Drosophila TDP-43 ortholog (dTDP) and transgenic expression of human TDP-43. The major findings of these complementary studies were largely consistent with one other. Flies lacking dTDP appeared externally normal but presented deficient locomotive behaviors, reduced life span, anatomical defects at the neuromuscular junctions and decreased dendritic branching 
(Feiguin, et al., 2009; Lin, et al., 2011; Lu, et al., 2009). These phenotypes were rescued by expression of the human TDP-43 protein in a restricted group of neurons including motor neurons (Feiguin, et al., 2009). These findings support the notion that loss of normal TDP-43 function may contribute to the pathogenesis of ALS and FTLD. On the other hand, ubiquitous or tissue-specific overexpression of either dTDP or human TDP-43 also recapitulated key hallmark features of ALS pathology including premature lethality, neuronal loss, neuromuscular junctions architecture defects and locomotor deficits (Elden, et al., 2010; Estes, et al., 2011; Hanson, et al., 2010; Li, et al., 2010; Lu, et al., 2009; Miguel, et al., 2011; Ritson, et al., 2010; Voigt, et al., 2010). Furthermore, TDP-43 expression appears to be independent of ALS/FTLD-linked mutations (Elden, et al., 2010; Estes, et al., 2011; Ritson, et al., 2010; Voigt, et al., 2010). These results also support the view of a toxic dominant gain-offunction mechanism(s) associated with TDP-43 proteinopathies.

To further explore the role of TDP-43 pathogenesis and identify pathogenic mechanisms, several independent research groups have used different genetic approaches to identify modifier genes that could suppress or enhance TDP-43 toxicity (Elden, et al., 2010; Hanson, et al., 2010; Ritson, et al., 2010). Interestingly, upregulation of Pab1-binding protein 1 (Pbp1), an ortholog of the human ATXN2 gene, in a transgenic model of TDP-43 enhanced TDP-43 toxicity and led to a more severe TDP-43 associated phenotypes (Elden, et al., 2010). Similarly, overexpression of ubiquilin 1, a previously identified TDP- 43 interacting partner (Kim, et al., 2009), reduced steady-state TDP-43 expression but enhanced the severity of TDP-43 phenotypes (Hanson, et al., 2010). Another study also showed that the TDP-43 associated phenotypes observed in a transgenic Drosophila TDP-43 model was modulated by coexpression of valosin-containing protein (VCP), a member of the ATPases associated with multiple cellular activities (AAA+) family of proteins regulating a wide array of cellular processes (Ritson, et al., 2010). Further investigations on these interesting findings may enable the development of novel therapeutics targets that can regulate TDP-43 expression in patients and hopefully delay or cure TDP-43-linked patients.

\subsubsection{Drosophila FUS models}

The pathogenic mechanisms underlying FUS proteinopathy remain largely unknown, although it is clear that FUS mutations affects motor neurons and other neuronal populations such as cortical neurons. In order to study FUS related function in vivo, a FUS/TLS Drosophila model was generated in which targeted expression of mutant human FUS/TLS (R518K, R521C and R521H) caused severe neurodegeneration in Drosophila eyes, whereas expression of WT human FUS/TLS resulted in very mild eye degeneration (Lanson, et al., 2011). Locomotor dysfunction and premature lethality was also observed in the mutant FUS/TLS transgenic flies. In addition, overexpression of mutant FUS/TLS caused an accumulation of ubiquitinated proteins, a pathological hallmark feature of ALS. Similarly, a pathogenic role of human ALS-associated FUS/TLS mutations (R524S and P525L) using Drosiphila has been described (Chen, et al., 2011). In this model overexpression of either Wt or ALS-mutant in different neuronal subpopulations, including photoreceptors, mushroom bodies and motor neurons led to an age-dependent progressive neuronal degeneration, including axonal loss, morphological changes and functional impairment in motor neurons. The human FUS/TLS drosophila ortholog (caz) has been also disrupted in order to study FUS function. The caz deficient fly exhibited reduced life span and locomotor deficits as compared with controls. Interestingly, these phenotypes were fully rescued by WT human FUS, but not ALS-associated mutant FUS proteins suggesting 
that ALS-associated FUS/TLS mutations are toxics (Walker, et al., 2011). Through crossrescue analysis, it has been demonstrated that FUS acted together with and downstream of TDP-43 in a common genetic pathway in neurons. Furthermore, the authors found that these proteins associated with each other in an RNA-dependent complex. These results establish that FUS and TDP-43 function together in vivo and suggest that molecular pathways requiring the combined activities of both of these proteins may be disrupted in ALS and FTD.

\subsection{Vertebrate models}

Projecting the human genome sequence into our understanding of human health and disease has been a new challenge faced in the post-genomic era. As described above, unicellular and invertebrate model systems can be of great value in defining the molecular components of pathways or processes that depend on the function of several interacting proteins. However, vertebrate models offer the best opportunity for defining landmarks of disease progression and for understanding the functional consequences of gene mutations. The great advantage of using vertebrates to model human diseases is clearly the possibility they offer for evaluation of new treatments. Indeed, testing new drugs on mice or other vertebrate models is often mandatory and asked by the Food and Drug Administration, for safety reasons, prior to approve new drug treatments. This step is also fundamental for paving the way towards human clinical trials, with both larger and smaller vertebrate model organisms.

Other advantages of using vertebrate models include: the ability to make efficient targeted gene knockouts by homologous recombination, they are evolutionary closer to human, the developmental overview is similar for all mammals, the availability of material at all stages of development, their brains are more similar to human, they respond to injury and can be conditioned (great advantages to study learning, neuronal connectivity and plasticity) and they provide a valuable source of primary cells for culture. The later feature will be discussed in more details in the next section of this book chapter.

On the contrary, the high maintenance cost, a relatively slow life cycle development, lower number of progeny, genetically identical offspring more difficult to obtain and the difficulty to manipulate embryos (intrauterine development) represent the major disadvantages of using vertebrate as disease model organisms.

\subsubsection{Mice}

Over the past century, the laboratory mouse (Mus musculus) has become the premier mammalian model organism for experimental studies and genetic research. Scientists from a wide range of biomedical fields have used the mouse because of its close genetic and physiological similarities to humans, as well as the ease with which its genome can be manipulated and analyzed, ease of handling and it's relatively high reproductive rate. Although yeasts, worms and flies are excellent models for studying many developmental processes, mice are far better models for studying diverse physiological systems such as the immune system, the endocrine system, the nervous system, the cardiovascular system, the skeletal system and other complex physiological systems that mammals share. Like humans and many other mammals, mice naturally develop diseases that affect these systems, including cancer, atherosclerosis, hypertension, diabetes, osteoporosis and glaucoma. In addition, manipulating the mouse genome and environment can induce certain diseases that 
afflict humans but normally do not strike mice, such as cystic fibrosis, obesity, blindness, anxiety, aggressive behavior, alcoholism, drug addiction and neurodegenerative disorders such as Alzheimer's disease, Parkinson's disease, Huntington's disease and ALS. Immunodeficient mice can also be used as hosts to facilitate cancer and AIDS research.

Researchers have used a collection of innovative genetic technologies to produce custommade mouse models for a broad array of specific diseases, as well as to study the function of targeted genes. One of the most important technological advances has been the ability to produce transgenic mice, in which a new gene (cloned from human or other various species, wild-type or mutated) is inserted into the mouse's germline. Indeed, the 2007 Nobel Prize in Physiology and Medicine was awarded to Drs Mario R. Capecchi, Martin J. Evans and Oliver Smithies for their discoveries of principles for introducing specific gene modifications in mice by the use of embryonic stem cells. Even more potent approaches, it is now possible to knockout or to artificially drive the expression of an inserted gene in specific tissue or at various time during development or adulthood using the Cre/Loxp system (Sauer, 1998). There are many mouse models commercially available for genetic research including thousands of unique inbred strains and genetically engineered mutants.

Researches using the laboratory mouse led to major advances in our ability to treat a number of serious diseases and conditions. Genetically, mice are more closely related to humans than invertebrates in the sense that most human genes have functional mouse counterparts and the mouse genome is organized in a very similar manner to the human genome. The mouse and human genomes are approximately the same size. They most likely contain the same number of genes and show extensive synteny and conserved gene order. Importantly, mice have also genes that are often not represented in other models, such as $C$. elegans and Drosophila. All these advantages make the laboratory mouse the model organism of choice to study human diseases. Although mice are widely used in research, questions remain however about their reliability as a model for human diseases. In occurrence, how to explain that many drugs worked well during preclinical trials in mice, but turned out to be ineffective when used in clinical trials on humans? Here, we will review the mouse studies that contributed toward understanding the pathogenic pathways of motor neuron disease and the testing of therapeutic approaches.

\subsubsection{Mice SOD1 models}

The use of mouse models has been of particular importance in studying the pathogenesis of Amyotrophic Lateral Sclerosis. The initial description of SOD1 gene mutations in familial ALS patients, in 1993, first led to the hypothesis that the disease resulted from compromised enzymatic activity due to the loss of the enzyme function (Rosen, et al., 1993). However, this loss of function hypothesis was rapidly refuted, as Sod1 KO mice in which the murine Sod1 gene was disrupted, do not develop disease (Reaume, et al., 1996). To date, over 150 different SOD1 missense mutations have been reported. In contrast, transgenic mice ubiquitously overexpressing various SOD1 gene mutations with different biochemical properties, even in the presence of endogenous mouse Sod1 gene, develop a neurodegenerative disease that is quite similar to the human illness. Of particular interest, transgenic mice overexpressing WT human SOD1 or specifically expressing mutant SOD1 only in neurons or only in glial cells do not develop disease (Bruijn, et al., 1998; Gong, et al., 2000; Pramatarova, et al., 2001). A toxic gain-of-function rather than a loss-of-function of mutant SOD1 gene is therefore believe to be involved in ALS-linked SOD1 patients. All published mouse models have used the endogenous murine Sod1 promoter resulting in high 
levels of expression of the mutant transgene in all tissues. Although these models implicate mutant SOD1 in the development of motor neuron degeneration, many questions regarding the mechanism of pathogenesis remain unanswered. One of the central mysteries in ALS research is why an ubiquitously expressed gene such as SOD1 causes selective devastation to motor neurons in the absence of pathology in other tissues. One possible explanation is that expression of the mutant protein in motor neurons may not be sufficient to lead to the development of a neurodegenerative disease in mice, suggesting that mutant SOD1 expression in other cells may be necessary for the development of the disease. Although there are indications that neurodegeneration in ALS may not strictly result from a cellautonomous process, the selective motor neuron vulnerability observed in the disease pathogenesis remains enigmatic.

The favored hypothesis at this time of SOD1-mediated disease is that toxicity of SOD1 mutants is related to the misfolding and aggregation of SOD1 species (Gros-Louis, et al., $2009 \mathrm{~b}$ ). However, it is not clear which conformational SOD1 species and oligomers cause ALS and the exact mechanism of toxicity of the misfolded SOD1 species remains unknown. Deleterious effects could result from the interaction of misfolded SOD1 species with essential cellular components such as Bcl-2 (Pasinelli, et al., 2004), from their recruitment to outer membrane of mitochondria or from overwhelming the capacity of the protein folding chaperones and/or of ubiquitin proteasome pathway to degrade important cellular regulatory factors (Turner, et al., 2005; Urushitani, et al., 2008; Urushitani, et al., 2002). The misfolded SOD1 protein may also form aggregates that might sequester important cellular components causing cytotoxicity. Recent studies demonstrated that a fraction of SOD1 could be translocated via the ER-Golgi network and that chromogranins, which are abundant proteins in motor neurons, interneurons and activated astrocytes, may act as chaperone-like proteins to promote secretion of misfolded SOD1 mutants (Urushitani, et al., 2008; Urushitani, et al., 2006). Moreover, it has been reported that extracellular mutant SOD1 can induce microgliosis and motor neuron death (Urushitani, et al., 2006). Such ALS pathogenic mechanism based on toxicity of secreted SOD1 mutant is in line with findings that disease is not strictly autonomous to motor neurons and that toxicity can propagate from one cell to another. Interestingly, it has been proposed that endoplasmic reticulum (ER) stress response might exert a critical role in the disease pathogenesis. The ER is the site of synthesis and folding of secretory and membrane bound proteins. The capacity of the ER to process proteins is limited and the accumulation of misfolded proteins may activate different ER stress pathways. The challenges in the future are to find out which somatic insults are causing the initial protein change, and to discover ways of preventing the misfolded proteins from spreading through the nervous system.

The overexpression of either G37R, G85R, G86R, D90A, G93A, H46R/H48Q or H46R/H48Q/H63G/H120G, L126Z and G127X mutant SOD1 protein in mice leads to motor neuron degeneration (Borchelt, et al., 1994; Bruijn, et al., 1997; Gurney, et al., 1994; Jonsson, et al., 2004; Jonsson, et al., 2006; Ripps, et al., 1995; Tu, et al., 1996; Wang, et al., 2003; Wang, et al., 2002; Wong, et al., 1995). In all of these mouse models, massive death of motor neurons in the ventral horn of the spinal cord and loss of myelinated axons in ventral motor roots ultimately leads to paralysis and muscle atrophy. Histopathological findings observed in these transgenic animals include progressive accumulation of detergent-resistant aggregates containing SOD1 and ubiquitin, aberrant neurofilament accumulations in degenerating motor neurons. In addition to neuronal degeneration, similar to that observed 
in ALS patients, Golgi fragmentation and neuroinflammation noted by the presence of reactive astroglia and microglia in diseased tissue are also observed. However, the severity of the phenotype (in term of age of onset, disease progression and disease duration) varies from one model to another and may be dependant on mouse genetic background (HeimanPatterson, et al., 2005) and gene dosage. In deed, the life span of these ALS mice is inversely proportional to gene dosage, i.e. the number of transgene insertion within the mouse genome, leading to different steady state level of mutant SOD1 protein in the central nervous system. Such variation in the steady state protein levels must reflect different stabilities and degradation of the various human SOD1 mutants.

The G93A-SOD1 mouse line is currently the most widely used experimental model in ALS research and drug testing. Unfortunately, several pharmacological approaches tested so far have produced only modest beneficial effects. Riluzole, a glutamate antagonist, extended the life span of G93A-SOD1 mice by 10 to 15 days without affecting disease onset (Gurney, et al., 1996). Today, riluzole is the only drug currently approved for ALS treatment. This treatment only produces modest beneficial effect in some ALS patients. Interestingly, is has been shown that treatment with the ER stress-protective agent salubrinal attenuated disease manifestations and delayed progression in a G93A-SOD1 mouse model (Saxena, et al., 2006). This result suggests a role of ER stress in ALS. Furthermore, it has been also shown that immunization therapy, using specific anti-misfolded SOD1 monoclonal antibodies, succeeded in reducing the level of mutant SOD1 by $23 \%$ in the spinal cord of immunized animals, in delaying disease onset and in prolonging the lifespan of G93A-SOD1 mice in proportion to the duration of treatment (Gros-Louis, et al., 2010). These results suggest that accumulation of misfolded SOD1 species is toxic, and reducing the burden of these toxic species leads to beneficial effect. Interestingly, it has been recently reported that WT SOD1 can acquire properties of ALS-linked mutant SOD1 species possibly implying a shared pathophysiological pathway between SALS and FALS (Bosco, et al., 2010b; Ezzi, et al., 2007). Another study also demonstrated that WT SOD1 may acquire toxic properties upon oxidative damage and that WT SOD1 expression dramatically exacerbated disease in transgenic mice expressing mutant SOD1 forms such as A4V, G85R, L126Z, and G93A SOD1 mutants (Wang, et al., 2009b). It is noteworthy that overexpression of WT SOD1 conferred ALS disease to unaffected A4V SOD1 mice. Based on these results, the possibility that WT SOD1 may be a contributor of pathogenesis in sporadic ALS must be considered.

\subsubsection{Mice TDP-43 models}

As previously mentioned, several research groups have reported that dominant mutations in the TARDBP gene, which encodes for TDP-43, cause ALS (Kabashi, et al., 2008; Sreedharan, et al., 2008; Van Deerlin, et al., 2008). Following these initials studies, a number of TDP-43 ALS mouse model has been described. Embryonic lethality is observed in homozygous mouse knockouts for TDP-43 (Kraemer, et al., 2010; Sephton, et al., 2010; Wu, et al., 2010). The TDP-43 deficient embryos die at embryonic day 7.5 thereby demonstrating the essential function of TDP-43 protein in development. Mice heterozygous for TDP-43 disruption only exhibit subtle muscle weakness with no evidence of motor neuron pathology.

Many of the transgenic mouse lines overexpressing WT or mutant TDP-43 reported to date have showed some ALS features including early paralysis leading to premature death (Stallings, et al., 2010; Wegorzewska, et al., 2009; Wils, et al., 2010). These pan-neuronal TDP43 transgenic mouse models expressing high-level of either WT or mutant (A315T and 
M337V) TDP-43 transgene in neurons both showed aggressive paralysis accompanied by increased ubiquitination in specific neuronal populations (Stallings, et al., 2010; Wegorzewska, et al., 2009; Wils, et al., 2010; Xu, et al., 2010). However, many concerns have been raised regarding the biological validity of these models, as they do not completely mimics disease. Since TDP-43 is a moderately and ubiquitously expressed protein, restricted non-physiological neuronal expression of TDP-43 is one of them, along with the use of the TDP-43 cDNA as transgene and the lack of cytoplasmic ubiquitinated TDP-43 inclusions. In order to better mimic the ubiquitous and moderate levels of TDP-43 expression seen in humans, another transgenic mouse models have been generated allowing the expression of genomic TDP-43 fragments (Swarup, et al., 2011). This TDP-43 mouse model exhibited agerelated phenotypic defects as seen in the human condition including both cognitive and motor deficits. Other pathological features as seen in human patients were also observed including, cytoplasmic TDP-43-positive ubiquitinated inclusions, intermediate filament abnormalities, axonopathy and neuroinflammation. These phenotypes were more severe in the transgenic TDP-43 mutant (G348C and A315T) models than the transgenic TDP-43 WT model.

\subsubsection{Mice intermediate filament models}

Several transgenic mouse lines and knockout mice implicating different neurofilament subunits have been extensively studied over the past years (for complete review, see: (Julien and Kriz, 2006; Lariviere and Julien, 2004)). Even though genetic mutations in intermediate filament (IF) genes are not major causes of ALS, it is of potential relevance to ALS that transgenic mice with altered stoichiometry of neuronal intermediate filament develop pathological features of the disease (Beaulieu, et al., 2000; Beaulieu and Julien, 2003; Cote, et al., 1993; Millecamps, et al., 2006). Of particular interest was the finding that overexpression of WT peripherin, a type III intermediate filament, in NEFL null background mice caused age-dependant selective motor neurons degeneration (Beaulieu, et al., 1999). This mouse model is also characterized by the formation of perikaryal and axonal intermediate filament inclusions resembling spheroids in motor neurons of human ALS. The precise mechanism by which accumulation of intermediate neurofilament leads to neurodegenerative disorders is not fully understood. Neurofilament and peripherin proteins are two types of intermediate filaments detected in the majority of axonal inclusion bodies, called spheroids, in motor neurons of ALS patients (Corbo and Hays, 1992). Multiple factors can potentially cause the accumulation of intermediate filament proteins including deregulation of intermediate filament protein synthesis, proteolysis, defective axonal transport, abnormal phosphorylation, and other protein modifications.

\subsubsection{Mice ALS2 models}

Truncating mutations were discovered in coding exons of a the ALS2 gene encoding for Alsin, from patients with an autosomal recessive form of juvenile ALS, primary lateral sclerosis (PLS) and infantile-onset ascending hereditary spastic paralysis (IAHSP) (Devon, et al., 2003; Eymard-Pierre, et al., 2002; Eymard-Pierre, et al., 2006; Gros-Louis, et al., 2003; Hadano, et al., 2001; Kress, et al., 2005; Yang, et al., 2001). The pattern of inheritance and the nature of the mutations identified in this gene suggest that motor neuron degeneration seen in patients results from a loss of protein function. Six different groups have reported the generation of an alsin knockout mouse (Cai, et al., 2005; Deng, et al., 2007; Devon, et al., 2003; Gros-Louis, et al., 2008; Hadano, et al., 2006; Yamanaka, et al., 2006). Despite an age- 
dependent loss of motor coordination revealed by rotarod and grip strength performances of the Als2 $\mathrm{KO}$ mice, no major motor deficits consistent with ALS or other motor neuron diseases were present in these models. All Als2-deficient mice appear to be grossly normal, viable and fertile with lifespan expectancy similar to WT littermates. However, some differences are noteworthy and may explain the heterogeneity of the phenotype, ranging from ALS to less severe PLS or IAHSP. The diversity of the apparent phenotypes among different Als2 KO mouse models may be due in part by different gene targeting strategies used to generate each mice models, ES cell lines used leading to differences in the genetic background, housing conditions or approaches taken to evaluate the mice.

Interestingly, thorough molecular analysis of one of these Als2 $\mathrm{KO}$ mouse model revealed the presence of a number of novel Als2 isoforms expressed in the central nervous system of these animals (Gros-Louis, et al., 2008). These results suggest that other alternatively spliced Als2 isoforms may exist and that some of these novel Als2 mRNA species still can be transcribed in Als2 null animals and may compensate for the loss of the full-length protein.

\subsubsection{Mice models associated with other motor neuron diseases}

Different other transgenic mice models overexpressing different human proteins either ubiquitously or specifically in neurons have been generated (for review see (Gros-Louis, et al., 2006; Julien and Kriz, 2006). These mice acquire age-dependent central nervous system pathology similar to other related motor neuron diseases such as FTDP17, progressive supranuclear palsy, spinal muscular atrophy or hereditary spastic paraplegia. Interesting pathological features, which are also associated with ALS, can be seen in these different mouse models including axonal degeneration in brain and spinal cord, progressive motor disturbance, behavioral impairment, and the presence of cellular aggregates and intermediate filament inclusions.

\subsubsection{Rat}

As a model of human disease, the laboratory rat (Rattus norvegicus) offers some advantages over the mouse and other organisms. The main advantage is in fact that rats are physiologically more similar to humans compare to mice. The size of the animal also confers a valuable advantage and enhances its use as a disease model. The later advantage is especially true when performing surgical procedures, microdialysis, intravenous cannulation and for pharmacodynamic drug studies as its size enables serial blood sampling. Thereby, the rat would be a better model than the mouse to study cardiovascular disease, hypertension, diabetes, arthritis, and many autoimmune, behavioral, and addiction disorders. The rat is also a good model in neurobehavioral and stereotaxic neurological studies. The size of the rat brain offers unique possibilities for the application of microsurgical techniques, intrathecal administration of drugs, stem cell transplantation, serial sampling of the cerebrospinal fluid (CSF), in vivo nerve recordings, and neuroimaging procedures.

However, even though its size is considered as an advantage over mice, the higher cost of maintenance (bigger cages, food, less animals can be housed per cages) and limited housing capacity in animal facilities directly related to its size also confers the principal limitation of using rats as a model.

\subsubsection{Rat SOD1 models}

Transgenic rat models of ALS have also been generated. In these models overexpression of G93A or H46R mutant SOD1 led to an ALS-like phenotype (Howland, et al., 2002; Nagai, et 
al., 2001). These transgenic rat models reproduce the major phenotypic features of human ALS, such as selective motor neuron loss, ubiquitination, hyaline inclusions, vacuolation, and neuroinflammation. However, several differences between the rat and mouse ALS models can be denoted including a more rapid progression of disease and the transient appearance of vacuoles in the transgenic SOD1 rats. As the CSF volume of a rat is 10- to 20fold greater than that of a mouse (Nagai, et al., 2001), transgenic SOD1 rats may facilitate to study the CSF proteome and to detect SOD1 activity or drug concentrations, even in an agedependent manner. Therefore, ALS rat models may be useful to demonstrate therapeutic efficacy, blood-brain barrier filtration and to assess the toxicity of novel therapeutic compounds in drug development.

\subsubsection{Rat TDP-43 models}

In order to generate a TDP-43 rodent model that is more suitable for pharmacological studies, rat models ubiquitously overexpressing either WT TDP-43 or the M337V-associated TARDBP mutation were generated (Zhou, et al., 2010). In contrast to what it is observed in TDP-43 transgenic mouse models, overexpression of mutant TDP-43 only, but not the WT protein, caused widespread neurodegeneration. Despite the fact that this transgenic mutant TDP-43 rat model exhibited progressive degeneration of motor neurons, neurodegeneration was not only restricted to motor neurons. However, TDP-43 mutation affected motor neurons earlier and more severely than other neurons in the CNS at end stage of the disease. In some aspects, this rat model recapitulated TDP-43 pathological features both seen in the different mouse models and in ALS patients indicating that this model could be used in future pharmalogical studies in order to identify novel therapeutic avenues to treat TDP-43 related disorders.

\subsubsection{Zebrafish}

In the last decade, a new vertebrate model has emerged in the study of human diseases. The principal attraction of using zebrafish (Danio renio) as model organisms is that its genome can be much more easily manipulated and studied in terms of genetics and development than other vertebrate model organisms. As being a vertebrate with common organs and tissues with conserved organization such as brain and spinal cord, the attractiveness of zebrafish to model human diseases lies therefore in its biology and genetics. Although there are obvious differences in the physiology of fish and humans the zebrafish offers several advantages that make it an important complement to mouse models of disease. These advantages include the embryo and larvae optical clarity (which allows easy visualization of developmental processes), the external fertilization (which facilitates gene expression manipulation), high fecundity (adult female can lay hundreds of eggs per day), and rapid development (swimming behavior appears less than 48 hours post-fertilization). As in invertebrate models, it is also relatively easy to perform forward and reverse genetic screens for gene identification and to understand specific gene function.

Forward-genetic screens in zebrafish, using random mutagenesis, can be used to identify novel genes involved in embryogenesis, organogenesis or different specific biological processes. To generate mutants, male fish are exposed to the mutagen ethyl-nitroso-urea (ENU), which typically induces point mutations within zebrafish genome (Driever, et al., 1996; Haffter, et al., 1996; Henion, et al., 1996; Solnica-Krezel, et al., 1996). Random mutagenesis has also been successfully carried out in zebrafish using retroviral methods (Amsterdam, et al., 1999). Treated males are then crossed to wildtype females to produce the 
F1 heterozygous progeny and so on so forth in order to generate homozygous progeny and to facilitate the identification of gene mutation by positional cloning. Forward-genetic screens in zebrafish are greatly facilitated by the transparency of embryos and larvae, simplifying phenotypic screening and allowing large scale screening without sophisticated expansive equipments. These features provide an advantage over other vertebrate models in which aspects of organogenesis and disease pathology cannot be examined without surgical interventions. Large-scale forward-genetic screens have allowed the identification of numerous mutations in zebrafish genes (Amsterdam and Hopkins, 2006). Comparative genomic can be then used in order to identify the corresponding orthologous gene in humans and, in some instances, the mutant phenotypes have been sufficiently similar to the human pathology to allow the identification of gene mutations by a candidate gene approach.

On the other hand, reverse genetics refers to the study of the phenotypic consequences following manipulation of gene expression. An essential tool for investigating gene function during development is the ability to perform gene knockdown, overexpression, and misexpression studies. The external egg fertilization in zebrafish enables microinjection of RNA, DNA, proteins, antisense oligonucleotides and other small molecules into the developing embryo thereby providing researchers a quick and robust assay for exploring gene function in vivo. Antisense morpholino oligonucleotides (AMO) are now widely used to modify gene expression by blocking translation of a targeted protein or by modifying premRNA splicing (Nasevicius and Ekker, 2000)). The ability to examine the course of a pathological process in vivo and in real time using AMO reverse genetic is a particular strength of zebrafish models. In particular, AMO are powerful reverse genetic tools for the biological validation of genetic variants identified in human and for defining the pathological nature of a particular gene mutation (Amsterdam and Hopkins, 2006). Finally, high-throughput screening for small-molecule chemical able to modify disease pathogenesis, firmly establishing a role for zebrafish in the field of pharmaceutical drug discovery.

\subsubsection{Zebrafish SOD1 models}

In order to generate a SOD1 zebrafish model of ALS, transient overexpression of human SOD1 mutants (A4V, G37R and G93A) was achieved using mRNA microinjection into 2 to 4 cell stage blastulae (Lemmens, et al., 2007). Overexpression of mutant human SOD1 in zebrafish embryos induced a dose-dependant motor axonopathy in all studied mutations. Likewise in ALS patients, ubiquitous expression of the mutant protein produced motor neuron specific neuropathology, suggesting that this model may be useful to elucidate the mechanisms underlying specific vulnerability of motor neurons in SOD1-linked ALS. Interestingly, the observed motor neuron phenotype in this transient SOD1mutant zebrafish embryo expresser suggests that ALS may be a developmental disease.

With the goal of achieving constitutive mutant SOD1 expression in zebrafish, Ramesh and colleagues generated transgenic zebrafish models overexpressing either WT or mutant SOD1 (Ramesh, et al., 2010). Zebrafish overexpressing mutant SOD1 exhibited many hallmark phenotypes of ALS including neuromuscular junction defects, spinal motor neuron loss, muscle degeneration, decreased endurance to swim, partial paralysis and premature death. Interestingly, all of these pathological features are consistent with those seen in SOD1 transgenic mice and rats, supporting the idea that overexpression of SOD1 in vertebrate models results in the development of common pathologies. As zebrafish are 
highly amenable to chimeric analysis, this zebrafish model will offer a tool to hopefully address in future studies the cell autonomous hypothesis seen in SOD1-linked ALS.

\subsubsection{Zebrafish TDP-43 models}

In order to test the toxicity associated with various TARDBP mutations (A315T, G348C and A382T), transient overexpression of WT and mutant TDP-43 was achieved by TARDBP mRNA microinjection (Kabashi, et al., 2010). Mutant TDP-43 overexpression resulted in motor neuron defects, including shorter axons, abnormal axonal branching and swimming deficits in the absence of sensory deficits. These phenotypes were also observed in WT TARDBP overexpressing zebrafish, but were less severe. These results confirmed that the studied TARDBP mutations are toxic and suggested that TDP-43 linked mutations preferentially target motor neurons for degeneration. Interestingly, knocking down the zebrafish Tardbp gene (zTardbp), using a specific AMO designed to block zTardbp translation, led to a similar phenotype, which was rescued by co-expressing WT but not mutant human TDP-43 (Kabashi, et al., 2010). Together these two reverse genetic approaches showed that TARDBP mutations cause motor neuron defects and toxicity, suggesting that mutant TDP43 contributes to disease pathogenesis by both a toxic gain-of-function and a loss-of-function molecular mechanisms.

\subsubsection{Zebrafish FUS models}

To test the FUS/TLS-linked mutations toxicity, transient expression of mRNAs encoding green fluorescent protein (GFP)-FUS (WT, H517Q, R521G, R495X or G515X) fused proteins was achieved by injecting these mRNA into zebrafish eggs at the 1 to 2 cells stage of development (Bosco, et al., 2010a). Interestingly, the expression of human FUS WT and the H517Q and R521G mutants each exhibited a predominantly nuclear pattern in the spinal cord, whereas the R495X and G515X truncation mutants accumulated in the cytoplasm. Noteworthy, abnormal accumulation of protein in the cytoplasm has been frequently observed in post-mortem tissues collected from ALS patients. This phenotype was exacerbated after heat shock treatment. These results suggest that the studied FUS-linked mutations induce toxicity and that multiple factors may influence the subcellular localization of GFP-FUS in vivo, including various cellular stresses. Similarly, upon transient overexpression of a FUS-linked ALS mutation (R521H) in zebrafish embryos, motor deficits characterized by abnormal touch-evoke escape response was observed in 57\% of the mRNA injected zebrafish larvae as compared to $23 \%$ in controls (Kabashi, et al., 2011). These results, from both studies, indicate that ALS-linked FUS/TLS mutants can cause motor neuron deficits by a toxic gain-of-function. On the other hand, loss-of-function cannot be totally excluded as knockdown of the zebrafish Fus (zFus) gene, using antisense morpholino oligo, also yielded a motor phenotype characterized by a deficient touch-evoked escape response, reduced motor neuron outgrowth and axonal branching (Kabashi, et al., 2011). Interestingly, these phenotypes could be rescued upon co-expression of WT human FUS but not ALSlinked FUS/TLS mutations.

\subsubsection{Zebrafish ALS2 models}

To investigate ALS2 gene function and to elucidate if the identified mouse Als2 splicing isoforms may compensate for the loss of the full length protein in Als2 $\mathrm{KO}$ mice described earlier, a knock-down of the zebrafish Als2 ortholog (zAls2) in zebrafish was performed using an AMO directed against the start codon of the zAls2 gene (Gros-Louis, et al., 2008). 
Consistent with this hypothesis, Gros-Louis and colleagues found that the zAls2 knocked down zebrafish led to both severe developmental abnormalities and an obvious behavioral phenotype, including swimming impairment and motor neuron disruption. This model is still the only ALS2 animal model mimicking the severe motor neuron degeneration observed in ALS2 patients. Interestingly, some of these Als2 splice variants rescued the zebrafish phenotype suggesting that these identified spliced variants, observed in Als2 null mice and in ALS2 patients, prevented the Als2 KO mice from developing severe neurodegenerative disease. These findings may also explain the variable phenotype observed in ALS2-linked patients.

\subsubsection{Dog}

The domestic dog (Canis familiaris), with over 450 naturally-occurring hereditary diseases, is a valuable model organism for the study of human genetic diseases and complex traits. In humans, common diseases show complex modes of inheritance, and as a result, genetic analysis and gene mapping could be tedious. Rodent systems are more tractable genetically, but studies using transgenic mouse models represent an induction of a particular mutation rather than naturally arising alleles, and results are often of limited direct relevance to human disease because of profound differences in physiology. In contrast, the physiology, disease presentation and clinical response of dogs to drugs often mimic human diseases closely. The dog genome is similar in size to the human genome; containing an estimated 2.8 billion DNA base pairs (Lindblad-Toh, et al., 2005). Canine models have played an important role in advancing biomedical knowledge and techniques. Due to a long history of selective breeding, many breeds of dogs are naturally prone to genetic diseases including cancer, autoimmune and neurological disorders afflicting humans. These dog models, in which naturally occurring mutations in different genes was described, may help the study of genetic diseases difficult to study in humans. The structure of the canine population offers specific advantages for genetic mapping studies. The dog enjoys a genetic diversity unrivaled by any other mammalian species. A thousand centuries of directed breeding by humans has been responsible for that diversity leading to an unequaled variety of morphologies and behaviors, and also into a number of inherited diseases. The top 10 diseases in dogs include cancer, epilepsy, allergy, retinal disease, cataracts, and heart disease. Several of these diseases constitute also a major health concerns to humans.

The disadvantages of using dog as a model are its size, cost of maintenance and housing limitations in order to provide adequate area for the dogs to run. Furthermore, there use in research has been more controversial and of public concerns than other animal models because of an obvious emotional tie toward dogs.

\subsubsection{Dog SOD1 model}

A genome-wide association analysis reveals a SOD1 mutation in canine degenerative myelopathy (Awano, et al., 2009). This disease has been recognized for more than 35 years as a spontaneously occurring, adult-onset spinal cord disorder of dogs (Averill, 1973). The resequencing of the canine Sod1 gene revealed a recessive E40K missense mutation. Pathological studies of spinal cords from affected dogs showed myelin and axonal loss, SOD1-positive neuronal cytoplasmic inclusions similar to those seen in patients. The disease is also fatal in dogs and, typically, presents with progressive upper motor neuron spasticity and general proprioceptive ataxia in the pelvic limbs leading to paraplegia. Dogs develop disease generally around 8 years of age or older and disease duration will not exceed, if 
euthanasia is delayed, 3 years. These findings suggest that this disease afflicting dogs is closely related to ALS and identify canine degenerative myelopathy to be the first recognized spontaneously occurring animal model for ALS. The canine ALS model may be particularly valuable for evaluating therapeutic interventions as the environmental conditions and the SOD1 level of expression mimic better the human ALS situation.

\subsubsection{Pig}

Pigs, although not easily kept for laboratory research, are readily available for biomedical research through the large-scale industrial production of pigs produced for human consumption. Recent research has facilitated the biological experimentation with pigs, and helped develop the pig into a novel model organism for biomedical research.

The domesticated pig (Sus scrofa) shares several similarities with human, in particular the size of organs and various aspects of anatomy and physiology. The development of somatic cloning technology and the merger with techniques of targeted genetic modification and conditional gene expression will enhance the possibilities for creating useful models for human diseases in pigs. The pig has also evolved as the major target species for producing xenografts in order to provide appropriate human organs. The sequencing of the domestic pig genome has not yet been fully completed. However, initial draft revealed that the size and composition of the porcine genome is comparable to that of humans; comprising about 2.7 billion base pairs (Hart, et al., 2007). Furthermore, both gene content and sequence are highly conserved between pig and human. Detailed information on the porcine genome together with emerging transgenic technologies, such as siRNA or conditional knockouts will enhance our possibilities to create useful pig models. Other advantages of using domestic pigs to model human diseases include high fertility, great abundance, rapid growth, anatomy and physiology not too different from human and the possibility to introduce genetic modifications in its genome. The pig has been an essential and very successful model in biomedical research and is particularly suited to close the gap between basic research in current models and clinical application. The future will certainly see several promising porcine models for human diseases.

The high resemblance between the central nervous systems of humans and pigs makes the pig an ideal model organism for studying human neurodegenerative diseases. For neurodegenerative disorders such as ALS, Parkinson's disease and Alzheimer's disease, the pig may represent a model superior to other models presently available. Large animals, including pigs and non-human primates in neuroscience enable the use of conventional clinical brain imaging and the direct testing of surgical procedures. The evaluation of novel therapeutic avenues in an animal model with higher brain complexity will allow a more direct translation to human diseases.

\section{In vitro models to study ALS}

In vitro models are extremely helpful to study human diseases because they allow to analyze different cell types independently from each other and to perform dynamic studies on isolated cells. Moreover, diseased cells can be combined with healthy ones to better understand which cell type is the most critical in the different stages of the disease.

Some of these in vitro models were developed using the ALS animal models previously discussed. However, neural cells are impossible to obtain from patients and their extraction 
from post-mortem tissues is limited due to the difficulty to isolate living cells from adult brain or spinal cord, especially motor neurons.

Thus, such postmortem tissue biopsies are mostly used to perform histological and immunohistochemical, genetic as well as proteomic studies. More recently, they were also used to extract neural precursor cells that were further differentiated into motor neurons and glial cells to develop innovative models of the disease.

\subsection{Organotypic cultures of spinal cord slices}

The best way to preserve all the cellular content and the complex electrophysiological and biochemical organization of cells in the spinal cord is to maintain a whole tissue slice in an organotypic culture. In addition, organotypic slice cultures can be obtained from both embryos and postnatal animals, conferring a major advantage when using transgenic mice from which the disease genotype has to be ascertained after birth (Kosuge, et al., 2009; Mazzone and Nistri, 2011). After dissection of the lumbar spinal cord and removal of the meninges, 200 to $400 \mu \mathrm{m}$-thick transversal sections are sectioned and transferred into membrane inserts fitting six-well or 12-well culture plates (Caldero, et al., 2010). These organotypic cultures can be used for more than 2 months (Delfs, et al., 1989). Various types of molecules can be added in the culture medium, such as kainate or lithium, to modulate neurotoxicity (Caldero, et al., 2010; Mazzone and Nistri, 2011).

These tissue sections can then be used to perform various analysis like recording the neuron rhythmic activity by placing the tissue on a multielectrode array (Tscherter, et al., 2001; Young, et al., 2007), or studying real-time glutamate release using a biosensor and redox reaction current using a multichannel potentiostat (Mazzone and Nistri, 2011), in addition to the conventional immunohistochemical staining and electrophysiological recordings (Caldero, et al., 2010; Young, et al., 2007). Neonatal brainstem slices can be used to analyze excitotoxicity on hypoglossal motor neurons that control the respiratory drive. These neurons are particularly useful for electrophysiological studies because they exhibit a range of rhythmic patterns that will be altered during early onset of ALS (Cifra, et al., 2011a; Cifra, et al., 2011b).

Organotypic culture is a convenient culture system that closely reproduces the in vivo situation and allows dynamic studies with various drugs and useful analysis systems. However, it does not always fully recapitulate what is happening in vivo (Tovar, et al., 2009). In addition, it does not easily allow the study of different mixed cell combinations by removing or by adding specific cell types to the tissue slices. These organotypic spinal cord slice cultures are difficult to obtain from postmortem patients due to limited availability and it is obviously impossible to study disease progression using human spinal cord biopsies as opposed to biopsies obtained from animal models.

\subsection{Spinal cord cell cultures}

The isolation of individual cells is extremely useful to study various intracellular mechanisms from proliferation to mRNA expression, mitochondrial function, protein aggregation, intermediate filament assembly or axonal transport. However, neurons cannot proliferate and are difficult to maintain in culture. In addition, adult nervous tissues are difficult to access and the viability of the cells extracted from them is very low. Actually, most of the cells that can be maintained in culture after extraction are neural precursor cells (Haidet-Phillips, et al., 2011).

To overcome this limitation, embryos are preferred for nervous tissue harvesting. Indeed, at the E12-13 embryonic developmental stage, the spinal cord of mice embryos is easy to access 
and remove, and motor neurons, astrocytes and microglia can be extracted, purified and maintain in culture with high viability yields (Gingras, et al., 2007b; Sanelli, et al., 2007; Schnaar and Schaffner, 1981). These cells can be dissociated from the spinal cord and cultured together to facilitate motor neuron survival (Tradewell, et al., 2011; Tradewell and Durham, 2010). Motor neurons will be easy to identify because of their large cell body $(>20 \mu \mathrm{m}$ in diameter) and dendritic trees, and can be stained for expression of the transcription factor $\mathrm{Hb} 9$ and choline acetyltransferase, specific molecular markers of motor neuron (Fig 3) (Gingras, et al., 2007b; Tradewell, et al., 2011).

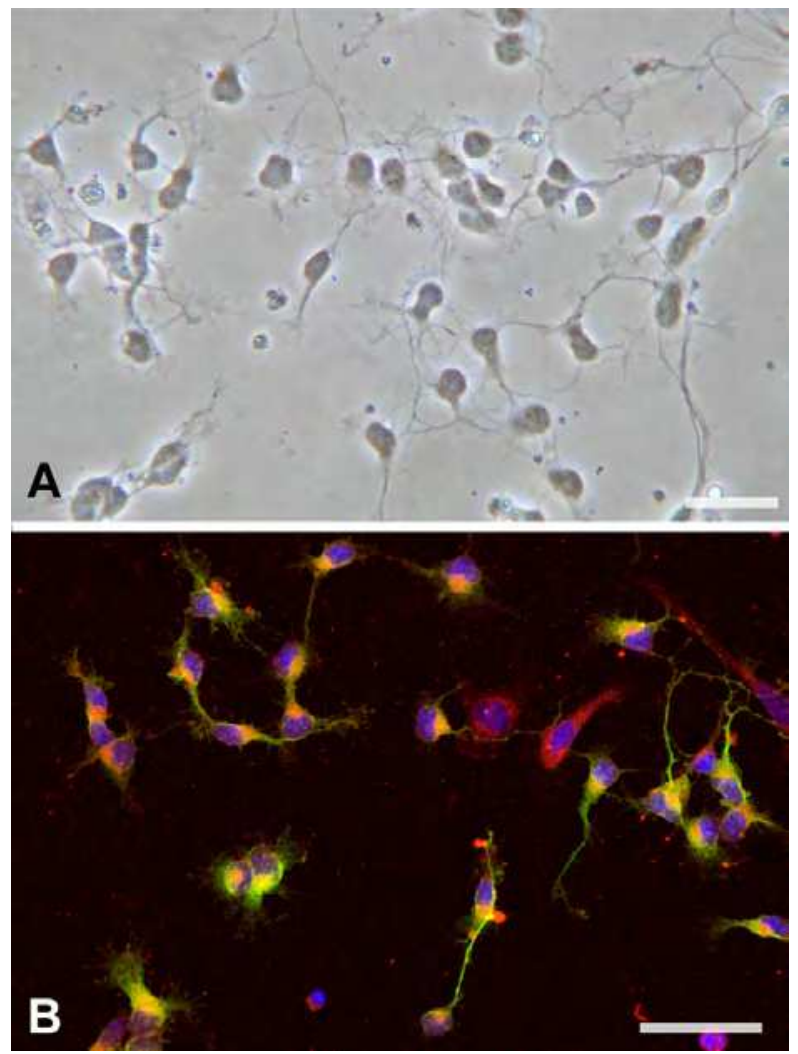

Fig. 3. E12 mouse embryo-purified motor neurons.

A: phase contrast microscopy of purified motor neurons $24 \mathrm{~h}$ after seeding. B: Motor neurons

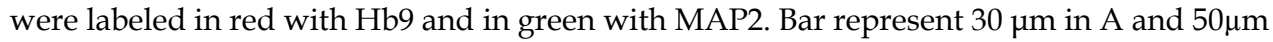
in B. Courtesy of Dr. Marie Gingras.

Cultures of purified motor neurons without the trophic support of glial cells are difficult to maintain for more than 2 weeks (Bar, 2000; Lunn, et al., 2009). In order to perform studies on a chronic disease like ALS, especially while looking for long-term cell survival effects, dissociated spinal cord cell cultures constitute a better choice as they can be maintain in culture for up to 7 weeks (Tradewell, et al., 2011). Purified motor neurons can also be cultured on an astrocyte feeder layer for several weeks on which they display characteristics 
(neurite pattern) closer to adult motor neurons (Bar, 2000). To reproduce an ALS phenotype, motor neurons can be induced to express multiple copies of the gene of interest, for example, mutated human G93A SOD1, by microinjection of the vectors into the cells identified by their specific morphology (Tradewell, et al., 2011; Tradewell and Durham, 2010). Motor neurons can also be purified and cultured separately, to allow their adenoviral transduction with G93A SOD1 (Lunn, et al., 2009), and then, to enhance their survival, they can be plated on a glial cell feeder layer treated with arabinofuranosyl cytidine (AraC), to prevent cell proliferation (De Paola, et al., 2008). These in vitro cultures are particularly useful to study cellular morphometry (axon length), gene expression using RT-PCR (ideally with only one purified cell type), apoptosis, signaling pathways, calcium imaging, mitochondrial membrane potential, glutamate uptake, excitotoxicity, etc.

The major drawbacks of spinal cord cell cultures are the need to perform cell extraction from embryos for each new experiment. In addition, cells cultured on plastic dishes cannot recapitulate the in vivo environment and some results obtained in vitro may not be reproducible in vivo at least in part because the complex interactions developed in the nervous system are lost. Furthermore, another disadvantage to use primary cells from embryos is that some features of the adult phenotype may not be expressed at this early stage (Park, et al., 2004).

\subsection{NCS-34 motor neuron cell line}

To greatly facilitate in vitro studies, motor neuron-enriched embryonic mouse spinal cord cells were fused with mouse neuroblastoma to generate the hybrid cell line NCS-34 (Cashman, et al., 1992; Durham, et al., 1993; Hunter, et al., 1991). This cell line contains small proliferative and undifferentiated cells and larger multinucleate cells. These cells express properties of motor neurons such as choline acetyltransferase, acethylcholine synthesis and neurofilament expression. They respond to agents affecting voltage-gated ion channels, cytoskeletal organization and axonal transport similarly with primary motor neurons, but failed to reproduce synaptic connections (Durham, et al., 1993). This cell line is widely used in several studies related to ALS (Foran, et al., 2011; Tabata, et al., 2008; Vijayalakshmi, et al., 2009; Yang, et al., 2010). For example, NCS-34 cells were treated with the cerebrospinal fluid (CSF) collected from sporadic ALS patients. It induced intracellular aggregates formation, ubiquitin immunoreactivity, neurofilament phosphorylation and choline acetyl transferase expression through induction of endoplasmic reticular stress. This effect was attenuated by addition of VEGF prior to exposition to CSF (Kulshreshtha, et al., 2011; Vijayalakshmi, et al., 2011; Vijayalakshmi, et al., 2009). NCS-34 cells can also be used to screen antioxidant molecules capable of rescuing them from expression of mutated SOD1 (Barber, et al., 2009).

\subsection{Xenopus oocyte model for electrophysiological recordings}

The Xenopus Laevi is an African frog from which the oocyte (egg) is a commonly used model for electrophysiological recording because of its large size (about $1 \mathrm{~mm}$ in diameter) which facilitates its handling. The oocyte has been used for decades to study various ion channels, transporters and receptors. This cell can be transduced with a molecules of interest for coexpression studies including the human glutamate transporter GLT1 (EAAT2) or NMDA receptors (Boehmer, et al., 2006; Texido, et al., 2011; Trotti, et al., 2001). This model has been used in some studies related to ALS, such as the analysis of the properties of the GLT1 transporter activities under controlled voltage clamp in presence or not of mutant SOD1 (Trotti, et al., 1999). 


\subsection{Neural precursor cells (NPCs) and induced pluripotent stem cells (iPS)}

One important advantage of in vitro cell cultures could gain over animal models would be to collect neural precursor cells directly from patients. These cells can be differentiated into all neural cell types, including motor neurons. As previously discussed, most of animal and cell culture models developed to study ALS so far were derived from known FALS-associated mutations in the SOD1, TARDBP or FUS/TLS genes. While these models are particularly useful to study FALS, they are not ideal for the study of SALS. Therefore, trying to understand the cause of the disease through the study of motor neurons and glial cells obtained from SALS patients would be challenging but potentially highly promising. However, motor neurons, and even glial cells are extremely difficult to isolate from brain and spinal cord samples obtained from post-mortem ALS patients.
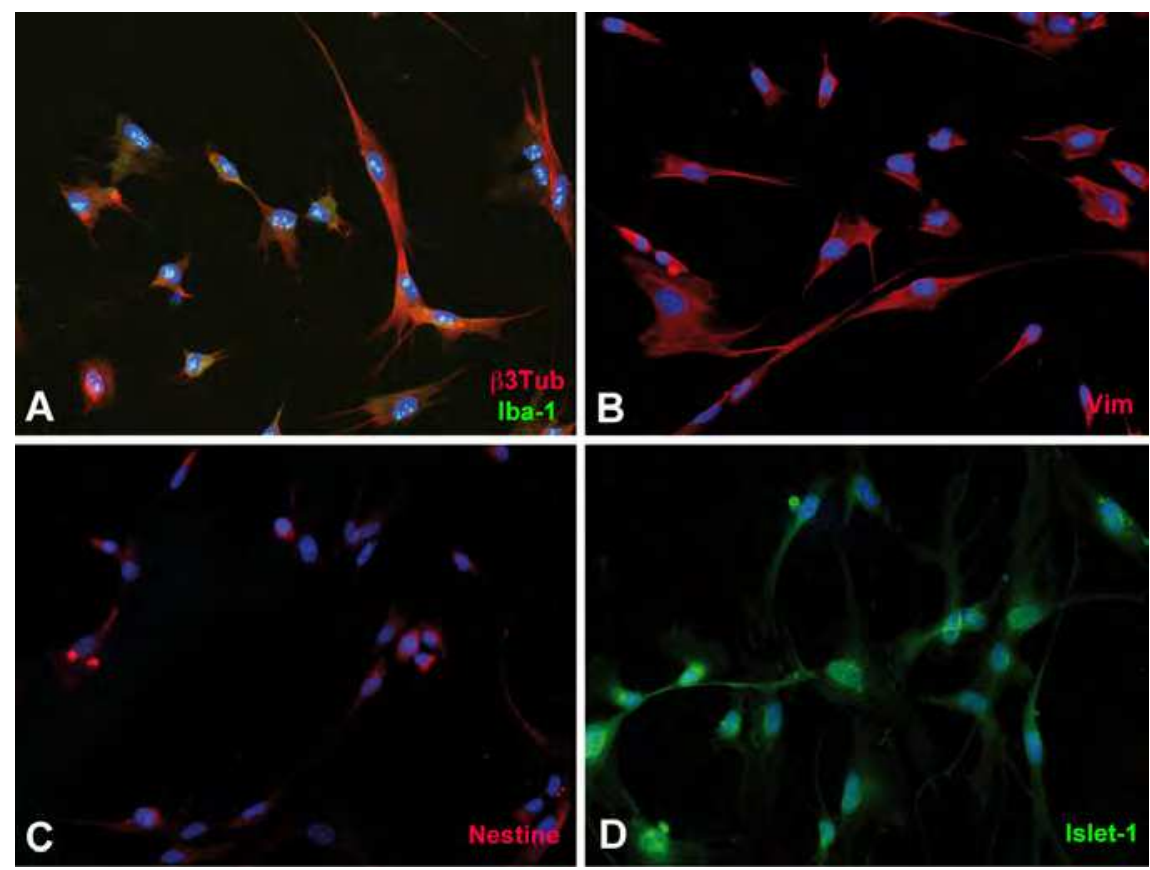

Fig. 4. Characterization of neural precursor cells (NPCs) extracted from postmortem ALS patient's spinal cord.

Cells express Iba1 (a marker of microglia) and $\beta 3$-tubulin (early marker of neuronal differentiation) (A), Vimentin (transiently expressed in neuronal precursors) (B), Nestin (transiently expressed in neuronal precursors) (C) and Islet-1 (an early marker for motor neuron differentiation) (C) that highlight their NPC status when co-expressed together in the same cells. Courtesy of Dr. Marie-Josée Beaulieu.

One very promising alternative is to take advantage of the neural precursor cells that can be extracted from adult tissues. Indeed, in a first step, the potential of mouse embryonic stem cells (ESCs) to differentiate into motor neurons has been well established (Wichterle, et al., 2002) and applied to the development of in vitro ALS models using ALS-linked G93A SOD1 gene mutation and WT SOD1 mouse embryos as source of stem cells (Di Giorgio, et al., 
2007). It was shown that G93A-SOD1 ESCs differentiated into motor neurons had a lower survival over 2 to 4 weeks in culture than their WT counterparts and showed ALS pathology hallmarks such as SOD1 protein aggregates and increase in activated caspase-3 expression after 21 days of culture (Di Giorgio, et al., 2007). Motor neurons have also been successfully differentiated from human ESCs (Hester, et al., 2011; Hu and Zhang, 2009). However, to obtain a source of multipotent stem cells from adult ALS patients, other approaches needed to be developed. These cells can be obtained from easily accessible tissues such as skin (Gingras, et al., 2007a; Toma, et al., 2001), but their limited proliferation capacity in vitro needs a relatively large amount of starting materials that up to now preclude their extraction from patients. Another possibility is to obtain postmortem biopsies of brain and spinal cord from ALS patients. It has been shown that if living glial cells and neurons are difficult to isolate from these tissues, neural precursor cells (NPCs) with a good proliferation rate are oppositely easy to purify and culture in vitro. These cells can then be differentiated in the cell type of interest. Neurons, astrocytes and oligodendrocytes were differentiated from NPCs purified from familial and sporadic ALS patient postmortem spinal cord samples (Fig 4) to study the toxic properties of patients-derived astrocytes on motor neurons (HaidetPhillips, et al., 2011). Both FALS and SALS-derived astrocytes were shown to be toxic to motor neurons, and the knock-down of SOD1 in SALS-derived astrocytes was demonstrated to attenuate this toxicity (Haidet-Phillips, et al., 2011). But postmortem tissues are difficult to obtain.

A much more versatile technique to generate multipotent stem cells from adults is to generate induced pluripotent stem cells (iPS cells) starting from somatic cells. This technique only requires a small punch biopsy of a few millimeters in diameter collected from the patient's skin, which will heal spontaneously without scarring. From this biopsy, dermal fibroblasts will be extracted and expanded to generate iPS cells. Generation of IPs cells is possible via overexpression of a defined set of transcription factors (c-Myc, Oct3/4, Klf4 and SOX2) (Takahashi, et al., 2007a; Takahashi, et al., 2007b). The genetic transduction of these oncogenes is usually achieved by using retroviral or lentiviral vectors. However, the use of integrating viral vectors represent a major obstacle to the therapeutic translation of iPS cells as this technology can produce insertional mutagenic lesions that are potentially tumorigenic. Other methods to reprogram cells are now being intensively tested, such as the use of secreted recombinant reprogramming factors present in the culture media. These iPS cells are morphologically and phenotypically similar to embryonic stem (ES) cells and thus offer exciting possibilities in stem cell research and regenerative medicine. This method has been successfully applied to ALS patients and allowed to study iPS-derived motor neurons in vitro (Dimos, et al., 2008; Mitne-Neto, et al., 2011). Since this technology is still recent, it is not clear whether motor neurons and glial cells derived from ALS patients-iPS cells will efficiently recapitulate the disease in vitro. However, these cells seem to behave like ESCs and even if they only partly mimic the ALS phenotype in culture, they certainly will be extremely interesting to use, especially for a better understanding of sporadic ALS.

\subsection{Three-dimensional in vitro models}

Now that iPS or NPCs ALS patient-derived motor neurons and glial cells will be available to develop better ALS in vitro models, their design could also be improved. The culture of neural cells in two dimensions on plastic does not mimic properly the in vivo situation. Building three-dimensional environment around ALS patient-derived neural cells could be a 
major improvement in the development of in vitro models of the disease. The culture of NPCs in methylcellulose scaffold enriched with laminin has been shown to reduce apoptosis and enhance survival, differentiation into neurons, astrocytes or oligodendrocytes and neurite extension (Cullen, et al., 2007; Stabenfeldt, et al., 2010). Motor neurons axonal migration can also be analyzed when these cells are cultured on the top of a threedimensional reconstructed connective tissue made of a collagen sponge populated with fibroblasts. The addition of neurotrophic factors underneath the construct promotes neurite growth from the top to the bottom of the tissue. The main advantage of this model is to enable myelin sheath formation by Schwann cells around axons in the connective tissue and the possibility to add various glial cells (astrocytes, microglia) in the motor neuron layer (Fig 5) (Gingras, et al., 2008). In addition, it is possible to easily combine cells from different origin, like WT motor neurons with ALS glial cells, and vice-versa in order to further explore the non-cell autonomous effect observed in SOD1-linked ALS pathology. Such combinations could also be very informative in the study of sporadic ALS. Alternatively, a 3 dimensional reconstructed muscle model has been developed to study in vitro the effect of muscle stretching on mRNA expression of muscle cells. This model was prepared using primary muscle cultures from human control subjects and ALS patients. The cells were embedded in a collagen gel tethered to a Culture Force Monitor to analyze gel contraction (Cheema, et al., 2003; Evans, et al., 2010).

Finally, the combination of ALS patient NPC-derived neural cells in tissue-engineered reconstructed spinal cord models is a promising strategy to develop the next generation of in vitro models of ALS.

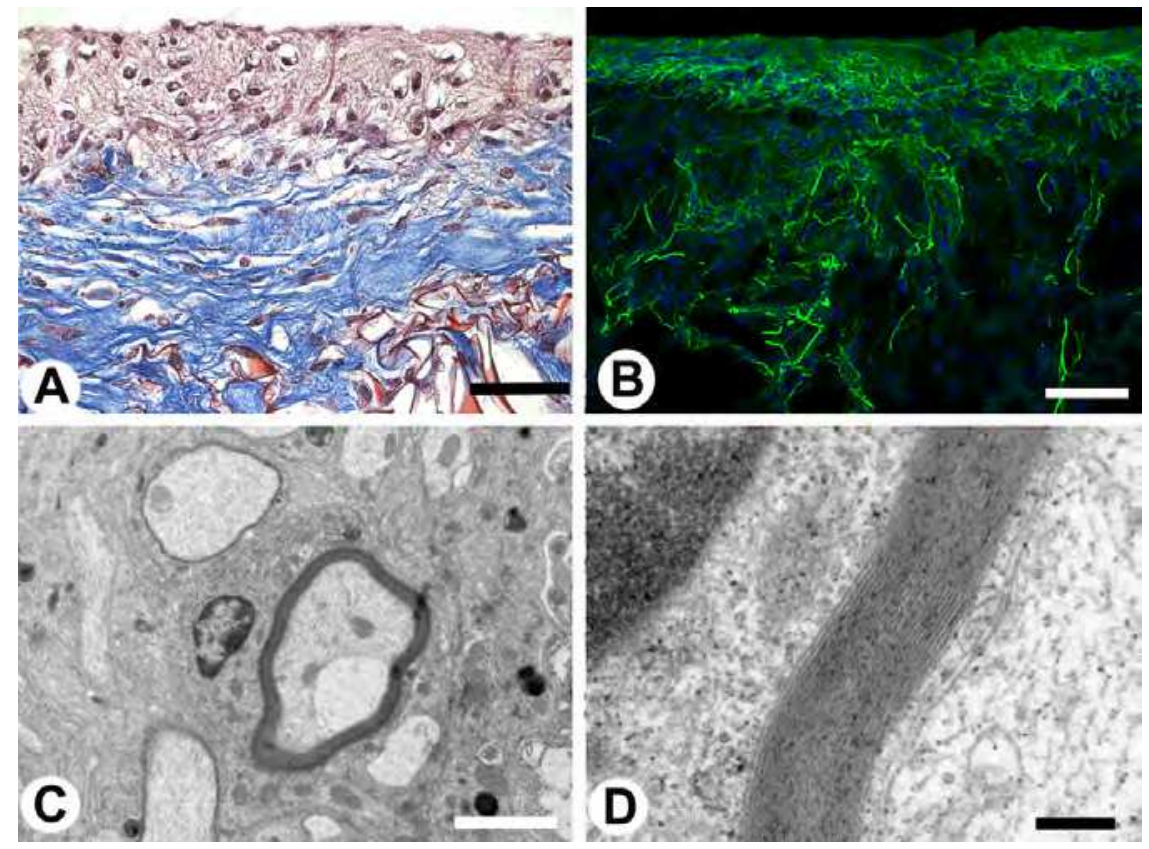

Fig. 5. Three-dimensional model of motor neuron axonal migration and myelin sheath formation. 
In A, after the culture of fibroblasts and Schwann cells for 21 days in a collagen sponge (blue area), mouse motor neurons were seeded on top of the sponge (purple area) and cultured for an additional 14 days and observed by histology staining with Masson's trichrom. In B, axonal migration (stained in green with an antibody against Neurofilament-M) originating from the top layer was shown migrating through the connective tissue. In $\mathrm{C}$, a transmission electron microscopic picture showed that some neurites were wrapped with thick myelin

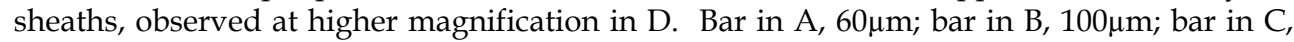
$2 \mu \mathrm{m}$; bar in F, 0,2 $\mu \mathrm{m}$ (Modified from Gingras, et al., 2008).

\section{Conclusion}

A very large body of knowledge has been built over the years with the development of various in vivo models to better understand ALS. Particularly, the generation of a large number of different transgenic mice has been extremely useful to study familial ALS, but has met with limited success so far to study SALS or to identify drugs alleviating the disease symptoms. This could be explained by the existence of redundant compensatory mechanisms present in higher vertebrates. The use of invertebrates together with higher animal models will hopefully allow the identification of novel pathogenic pathways and novel therapeutic avenues in order to cure this devastating disease.

In parallel, the development of in vitro models will give valuable information about the intracellular modulations induced by the disease. In addition, the promise of building sophisticated in vitro models using patient's cells will also be crucial to better understand the disease. However, the results obtained from in vitro models may not always be relevant because they are oversimplified compared to the in vivo situation. Therefore, the best strategy to reduce the limitations inherent to all these different models, and to benefit from their specific advantages is to combine both in vivo and in vitro models in order to better model the disease. Future work, focusing on different neuronal in vitro system and animal models, will certainly increases our knowledge in the biology of ALS and hopefully leads to more translational researches in order to find a cure or to slow down the course of this yet untreatable disease.

\section{Acknowledgment}

We would like to thank Dr. Alex J. Parker and Dr Guy A. Rouleau, from the Centre of Excellence in Neuromics, University of Montreal, Quebec, Canada, for having provided respectively the figure 1 and 2 of this book chapter. We also thank Marie Gingras and Marie-Josée Beaudet for their assistance in generating figure 3 to 5. Dr François Gros-Louis is supported by the Fond de la recherche en santé du Québec (FRSQ) and by the Fondation des hôpitaux Enfant-Jésus-St-Sacrement. Dr François Berthod is supported by the Muscular Dystrophy Association USA (www.mda.org). The authors declare no conflict of interest.

\section{References}

Adams, M. D., Celniker, S. E., Holt, R. A., Evans, C. A., Gocayne, J. D., Amanatides, P. G., Scherer, S. E., Li, P. W., Hoskins, R. A., Galle, R. F., George, R. A., Lewis, S. E., Richards, S., Ashburner, M., Henderson, S. N., Sutton, G. G., Wortman, J. R., Yandell, M. D., Zhang, Q., Chen, L. X., Brandon, R. C., Rogers, Y. H., Blazej, R. G., Champe, 
M., Pfeiffer, B. D., Wan, K. H., Doyle, C., Baxter, E. G., Helt, G., Nelson, C. R., Gabor, G. L., Abril, J. F., Agbayani, A., An, H. J., Andrews-Pfannkoch, C., Baldwin, D., Ballew, R. M., Basu, A., Baxendale, J., Bayraktaroglu, L., Beasley, E. M., Beeson, K. Y., Benos, P. V., Berman, B. P., Bhandari, D., Bolshakov, S., Borkova, D., Botchan, M. R., Bouck, J., Brokstein, P., Brottier, P., Burtis, K. C., Busam, D. A., Butler, H., Cadieu, E., Center, A., Chandra, I., Cherry, J. M., Cawley, S., Dahlke, C., Davenport, L. B., Davies, P., de Pablos, B., Delcher, A., Deng, Z., Mays, A. D., Dew, I., Dietz, S. M., Dodson, K., Doup, L. E., Downes, M., Dugan-Rocha, S., Dunkov, B. C., Dunn, P., Durbin, K. J., Evangelista, C. C., Ferraz, C., Ferriera, S., Fleischmann, W., Fosler, C., Gabrielian, A. E., Garg, N. S., Gelbart, W. M., Glasser, K., Glodek, A., Gong, F., Gorrell, J. H., Gu, Z., Guan, P., Harris, M., Harris, N. L., Harvey, D., Heiman, T. J., Hernandez, J. R., Houck, J., Hostin, D., Houston, K. A., Howland, T. J., Wei, M. H., Ibegwam, C., Jalali, M., Kalush, F., Karpen, G. H., Ke, Z., Kennison, J. A., Ketchum, K. A., Kimmel, B. E., Kodira, C. D., Kraft, C., Kravitz, S., Kulp, D., Lai, Z., Lasko, P., Lei, Y., Levitsky, A. A., Li, J., Li, Z., Liang, Y., Lin, X., Liu, X., Mattei, B., McIntosh, T. C., McLeod, M. P., McPherson, D., Merkulov, G., Milshina, N. V., Mobarry, C., Morris, J., Moshrefi, A., Mount, S. M., Moy, M., Murphy, B., Murphy, L., Muzny, D. M., Nelson, D. L., Nelson, D. R., Nelson, K. A., Nixon, K., Nusskern, D. R., Pacleb, J. M., Palazzolo, M., Pittman, G. S., Pan, S., Pollard, J., Puri, V., Reese, M. G., Reinert, K., Remington, K., Saunders, R. D., Scheeler, F., Shen, H., Shue, B. C., Siden-Kiamos, I., Simpson, M., Skupski, M. P., Smith, T., Spier, E., Spradling, A. C., Stapleton, M., Strong, R., Sun, E., Svirskas, R., Tector, C., Turner, R., Venter, E., Wang, A. H., Wang, X., Wang, Z. Y., Wassarman, D. A., Weinstock, G. M., Weissenbach, J., Williams, S. M., WoodageT, Worley, K. C., Wu, D., Yang, S., Yao, Q. A., Ye, J., Yeh, R. F., Zaveri, J. S., Zhan, M., Zhang, G., Zhao, Q., Zheng, L., Zheng, X. H., Zhong, F. N., Zhong, W., Zhou, X., Zhu, S., Zhu, X., Smith, H. O., Gibbs, R. A., Myers, E. W., Rubin, G. M. and Venter, J. C. (2000). The genome sequence of Drosophila melanogaster. Science, 287, 2185-95.

Amsterdam, A., Burgess, S., Golling, G., Chen, W., Sun, Z., Townsend, K., Farrington, S., Haldi, M. and Hopkins, N. (1999). A large-scale insertional mutagenesis screen in zebrafish. Genes Dev, 13, 2713-24.

Amsterdam, A. and Hopkins, N. (2006). Mutagenesis strategies in zebrafish for identifying genes involved in development and disease. Trends Genet, 22, 473-8.

Anonymous (1998). Genome sequence of the nematode C. elegans: a platform for investigating biology. Science, 282, 2012-8.

Ash, P. E., Zhang, Y. J., Roberts, C. M., Saldi, T., Hutter, H., Buratti, E., Petrucelli, L. and Link, C. D. (2010). Neurotoxic effects of TDP-43 overexpression in C. elegans. Hum Mol Genet, 19, 3206-18.

Averill, D. R., Jr. (1973). Degenerative myelopathy in the aging German Shepherd dog: clinical and pathologic findings. J Am Vet Med Assoc, 162, 1045-51.

Awano, T., Johnson, G. S., Wade, C. M., Katz, M. L., Johnson, G. C., Taylor, J. F., Perloski, M., Biagi, T., Baranowska, I., Long, S., March, P. A., Olby, N. J., Shelton, G. D., Khan, S., O'Brien, D. P., Lindblad-Toh, K. and Coates, J. R. (2009). Genome-wide association analysis reveals a SOD1 mutation in canine degenerative myelopathy that resembles amyotrophic lateral sclerosis. Proc Natl Acad Sci U S A, 106, 2794-9.

Bar, P. R. (2000). Motor neuron disease in vitro: the use of cultured motor neurons to study amyotrophic lateral sclerosis. Eur J Pharmacol, 405, 285-95. 
Barber, S. C., Higginbottom, A., Mead, R. J., Barber, S. and Shaw, P. J. (2009). An in vitro screening cascade to identify neuroprotective antioxidants in ALS. Free Radic Biol Med, 46, 1127-38.

Bargmann, C. I. (1998). Neurobiology of the Caenorhabditis elegans genome. Science, 282, 2028-33.

Beaulieu, J. M., Jacomy, H. and Julien, J. P. (2000). Formation of intermediate filament protein aggregates with disparate effects in two transgenic mouse models lacking the neurofilament light subunit. J Neurosci, 20, 5321-8.

Beaulieu, J. M. and Julien, J. P. (2003). Peripherin-mediated death of motor neurons rescued by overexpression of neurofilament NF-H proteins. J Neurochem, 85, 248-56.

Beaulieu, J. M., Nguyen, M. D. and Julien, J. P. (1999). Late onset of motor neurons in mice overexpressing wild-type peripherin. J Cell Biol, 147, 531-44.

Boehmer, C., Palmada, M., Rajamanickam, J., Schniepp, R., Amara, S. and Lang, F. (2006). Post-translational regulation of EAAT2 function by co-expressed ubiquitin ligase Nedd4-2 is impacted by SGK kinases. J Neurochem, 97, 911-21.

Boillee, S., Yamanaka, K., Lobsiger, C. S., Copeland, N. G., Jenkins, N. A., Kassiotis, G., Kollias, G. and Cleveland, D. W. (2006). Onset and progression in inherited ALS determined by motor neurons and microglia. Science, 312, 1389-92.

Borchelt, D. R., Lee, M. K., Slunt, H. S., Guarnieri, M., Xu, Z. S., Wong, P. C., Brown, R. H., Jr., Price, D. L., Sisodia, S. S. and Cleveland, D. W. (1994). Superoxide dismutase 1 with mutations linked to familial amyotrophic lateral sclerosis possesses significant activity. Proc Natl Acad Sci U S A, 91, 8292-6.

Bosco, D. A., Lemay, N., Ko, H. K., Zhou, H., Burke, C., Kwiatkowski, T. J., Jr., Sapp, P., McKenna-Yasek, D., Brown, R. H., Jr. and Hayward, L. J. (2010a). Mutant FUS proteins that cause amyotrophic lateral sclerosis incorporate into stress granules. Hum Mol Genet, 19, 4160-75.

Bosco, D. A., Morfini, G., Karabacak, N. M., Song, Y., Gros-Louis, F., Pasinelli, P., Goolsby, H., Fontaine, B. A., Lemay, N., McKenna-Yasek, D., Frosch, M. P., Agar, J. N., Julien, J. P., Brady, S. T. and Brown, R. H., Jr. (2010b). Wild-type and mutant SOD1 share an aberrant conformation and a common pathogenic pathway in ALS. Nat Neurosci, 13, 1396-403.

Brand, A. H. and Perrimon, N. (1993). Targeted gene expression as a means of altering cell fates and generating dominant phenotypes. Development, 118, 401-15.

Brenner, S. (1974). The genetics of Caenorhabditis elegans. Genetics, 77, 71-94.

Bruijn, L. I., Becher, M. W., Lee, M. K., Anderson, K. L., Jenkins, N. A., Copeland, N. G., Sisodia, S. S., Rothstein, J. D., Borchelt, D. R., Price, D. L. and Cleveland, D. W. (1997). ALS-linked SOD1 mutant G85R mediates damage to astrocytes and promotes rapidly progressive disease with SOD1-containing inclusions. Neuron, 18, 327-38.

Bruijn, L. I., Houseweart, M. K., Kato, S., Anderson, K. L., Anderson, S. D., Ohama, E., Reaume, A. G., Scott, R. W. and Cleveland, D. W. (1998). Aggregation and motor neuron toxicity of an ALS-linked SOD1 mutant independent from wild-type SOD1. Science, 281, 1851-4.

Cai, H., Lin, X., Xie, C., Laird, F. M., Lai, C., Wen, H., Chiang, H. C., Shim, H., Farah, M. H., Hoke, A., Price, D. L. and Wong, P. C. (2005). Loss of ALS2 function is insufficient to trigger motor neuron degeneration in knock-out mice but predisposes neurons to oxidative stress. J Neurosci, 25, 7567-74. 
Caldero, J., Brunet, N., Tarabal, O., Piedrafita, L., Hereu, M., Ayala, V. and Esquerda, J. E. (2010). Lithium prevents excitotoxic cell death of motoneurons in organotypic slice cultures of spinal cord. Neuroscience, 165, 1353-69.

Cashman, N. R., Durham, H. D., Blusztajn, J. K., Oda, K., Tabira, T., Shaw, I. T., Dahrouge, S. and Antel, J. P. (1992). Neuroblastoma x spinal cord (NSC) hybrid cell lines resemble developing motor neurons. Dev Dyn, 194, 209-21.

Cheema, U., Yang, S. Y., Mudera, V., Goldspink, G. G. and Brown, R. A. (2003). 3-D in vitro model of early skeletal muscle development. Cell Motil Cytoskeleton, 54, 226-36.

Chen, Y., Yang, M., Deng, J., Chen, X., Ye, Y., Zhu, L., Liu, J., Ye, H., Shen, Y., Li, Y., Rao, E. J., Fushimi, K., Zhou, X., Bigio, E. H., Mesulam, M., Xu, Q. and Wu, J. Y. (2011). Expression of human FUS protein in Drosophila leads to progressive neurodegeneration. Protein Cell, 2, 477-86.

Chio, A., Borghero, G., Pugliatti, M., Ticca, A., Calvo, A., Moglia, C., Mutani, R., Brunetti, M., Ossola, I., Marrosu, M. G., Murru, M. R., Floris, G., Cannas, A., Parish, L. D., Cossu, P., Abramzon, Y., Johnson, J. O., Nalls, M. A., Arepalli, S., Chong, S., Hernandez, D. G., Traynor, B. J. and Restagno, G. (2011). Large proportion of amyotrophic lateral sclerosis cases in Sardinia due to a single founder mutation of the TARDBP gene. Arch Neurol, 68, 594-8.

Chow, C. Y., Landers, J. E., Bergren, S. K., Sapp, P. C., Grant, A. E., Jones, J. M., Everett, L., Lenk, G. M., McKenna-Yasek, D. M., Weisman, L. S., Figlewicz, D., Brown, R. H. and Meisler, M. H. (2009). Deleterious variants of FIG4, a phosphoinositide phosphatase, in patients with ALS. Am J Hum Genet, 84, 85-8.

Christensen, M., Estevez, A., Yin, X., Fox, R., Morrison, R., McDonnell, M., Gleason, C., Miller, D. M., 3rd and Strange, K. (2002). A primary culture system for functional analysis of C. elegans neurons and muscle cells. Neuron, 33, 503-14.

Cifra, A., Nani, F. and Nistri, A. (2011a). Respiratory motoneurons and pathological conditions: Lessons from hypoglossal motoneurons challenged by excitotoxic or oxidative stress. Respir Physiol Neurobiol, doi:10.1016/j.resp.2011.03.017.

Cifra, A., Nani, F. and Nistri, A. (2011b). Riluzole is a potent drug to protect neonatal rat hypoglossal motoneurons in vitro from excitotoxicity due to glutamate uptake block. Eur J Neurosci, 33, 899-913.

Clement, A. M., Nguyen, M. D., Roberts, E. A., Garcia, M. L., Boillee, S., Rule, M., McMahon, A. P., Doucette, W., Siwek, D., Ferrante, R. J., Brown, R. H., Jr., Julien, J. P., Goldstein, L. S. and Cleveland, D. W. (2003). Wild-type nonneuronal cells extend survival of SOD1 mutant motor neurons in ALS mice. Science, 302, 113-7.

Corbo, M. and Hays, A. P. (1992). Peripherin and neurofilament protein coexist in spinal spheroids of motor neuron disease. J Neuropathol Exp Neurol, 51, 531-7.

Corrado, L., Ratti, A., Gellera, C., Buratti, E., Castellotti, B., Carlomagno, Y., Ticozzi, N., Mazzini, L., Testa, L., Taroni, F., Baralle, F. E., Silani, V. and D'Alfonso, S. (2009). High frequency of TARDBP gene mutations in Italian patients with amyotrophic lateral sclerosis. Hum Mutat, 30, 688-94.

Cote, F., Collard, J. F. and Julien, J. P. (1993). Progressive neuronopathy in transgenic mice expressing the human neurofilament heavy gene: a mouse model of amyotrophic lateral sclerosis. Cell, 73, 35-46.

Culetto, E. and Sattelle, D. B. (2000). A role for Caenorhabditis elegans in understanding the function and interactions of human disease genes. Hum Mol Genet, 9, 869-77. 
Cullen, D. K., Stabenfeldt, S. E., Simon, C. M., Tate, C. C. and LaPlaca, M. C. (2007). In vitro neural injury model for optimization of tissue-engineered constructs. J Neurosci Res, 85, 3642-51.

Daoud, H., Valdmanis, P. N., Kabashi, E., Dion, P., Dupre, N., Camu, W., Meininger, V. and Rouleau, G. A. (2009). Contribution of TARDBP mutations to sporadic amyotrophic lateral sclerosis. J Med Genet, 46, 112-4.

De Paola, M., Diana, V., Bigini, P. and Mennini, T. (2008). Morphological features and responses to AMPA receptor-mediated excitotoxicity of mouse motor neurons: comparison in purified, mixed anterior horn or motor neuron/glia cocultures. $J$ Neurosci Methods, 170, 85-95.

DeJesus-Hernandez, M., Mackenzie, I. R., Boeve, B. F., Boxer, A. L., Baker, M., Rutherford, N. J., Nicholson, A. M., Finch, N. A., Flynn, H., Adamson, J., Kouri, N., Wojtas, A., Sengdy, P., Hsiung, G. R., Karydas, A., Seeley, W. W., Josephs, K. A., Coppola, G., Geschwind, D. H., Wszolek, Z. K., Feldman, H., Knopman, D. S., Petersen, R. C., Miller, B. L., Dickson, D. W., Boylan, K. B., Graff-Radford, N. R. and Rademakers, R. (2011). Expanded GGGGCC Hexanucleotide Repeat in Noncoding Region of C9ORF72 Causes Chromosome 9p-Linked FTD and ALS. Neuron.

Delfs, J., Friend, J., Ishimoto, S. and Saroff, D. (1989). Ventral and dorsal horn acetylcholinesterase neurons are maintained in organotypic cultures of postnatal rat spinal cord explants. Brain Res, 488, 31-42.

Deng, H. X., Zhai, H., Fu, R., Shi, Y., Gorrie, G. H., Yang, Y., Liu, E., Dal Canto, M. C., Mugnaini, E. and Siddique, T. (2007). Distal axonopathy in an alsin-deficient mouse model. Hum Mol Genet, 16, 2911-20.

Devon, R. S., Helm, J. R., Rouleau, G. A., Leitner, Y., Lerman-Sagie, T., Lev, D. and Hayden, M. R. (2003). The first nonsense mutation in alsin results in a homogeneous phenotype of infantile-onset ascending spastic paralysis with bulbar involvement in two siblings. Clin Genet, 64, 210-5.

Di Giorgio, F. P., Carrasco, M. A., Siao, M. C., Maniatis, T. and Eggan, K. (2007). Non-cell autonomous effect of glia on motor neurons in an embryonic stem cell-based ALS model. Nat Neurosci, 10, 608-14.

Dimos, J. T., Rodolfa, K. T., Niakan, K. K., Weisenthal, L. M., Mitsumoto, H., Chung, W., Croft, G. F., Saphier, G., Leibel, R., Goland, R., Wichterle, H., Henderson, C. E. and Eggan, K. (2008). Induced pluripotent stem cells generated from patients with ALS can be differentiated into motor neurons. Science, 321, 1218-21.

Driever, W., Solnica-Krezel, L., Schier, A. F., Neuhauss, S. C., Malicki, J., Stemple, D. L., Stainier, D. Y., Zwartkruis, F., Abdelilah, S., Rangini, Z., Belak, J. and Boggs, C. (1996). A genetic screen for mutations affecting embryogenesis in zebrafish. Development, 123, 37-46.

Durham, H. D., Dahrouge, S. and Cashman, N. R. (1993). Evaluation of the spinal cord neuron X neuroblastoma hybrid cell line NSC-34 as a model for neurotoxicity testing. Neurotoxicology, 14, 387-95.

Elden, A. C., Kim, H. J., Hart, M. P., Chen-Plotkin, A. S., Johnson, B. S., Fang, X., Armakola, M., Geser, F., Greene, R., Lu, M. M., Padmanabhan, A., Clay-Falcone, D., McCluskey, L., Elman, L., Juhr, D., Gruber, P. J., Rub, U., Auburger, G., Trojanowski, J. Q., Lee, V. M., Van Deerlin, V. M., Bonini, N. M. and Gitler, A. D. (2010). Ataxin-2 intermediate-length polyglutamine expansions are associated with increased risk for ALS. Nature, 466, 1069-75. 
Estes, P. S., Boehringer, A., Zwick, R., Tang, J. E., Grigsby, B. and Zarnescu, D. C. (2011). Wild-type and A315T mutant TDP-43 exert differential neurotoxicity in a Drosophila model of ALS. Hum Mol Genet, 20, 2308-21.

Evans, R. M., Harridge, S. D., Velloso, C. P., Yang, S. Y., Goldspink, G. and Orrell, R. W. (2010). Investigation of MGF mRNA expression in patients with amyotrophic lateral sclerosis using parallel in vivo and in vitro approaches. Amyotroph Lateral Scler, 11, 172-7.

Eymard-Pierre, E., Lesca, G., Dollet, S., Santorelli, F. M., di Capua, M., Bertini, E. and Boespflug-Tanguy, O. (2002). Infantile-onset ascending hereditary spastic paralysis is associated with mutations in the alsin gene. Am J Hum Genet, 71, 518-27.

Eymard-Pierre, E., Yamanaka, K., Haeussler, M., Kress, W., Gauthier-Barichard, F., Combes, P., Cleveland, D. W. and Boespflug-Tanguy, O. (2006). Novel missense mutation in ALS2 gene results in infantile ascending hereditary spastic paralysis. Ann Neurol, 59, 976-80.

Ezzi, S. A., Urushitani, M. and Julien, J. P. (2007). Wild-type superoxide dismutase acquires binding and toxic properties of ALS-linked mutant forms through oxidation. $J$ Neurochem, 102, 170-8.

Feiguin, F., Godena, V. K., Romano, G., D'Ambrogio, A., Klima, R. and Baralle, F. E. (2009). Depletion of TDP-43 affects Drosophila motoneurons terminal synapsis and locomotive behavior. FEBS Lett, 583, 1586-92.

Fire, A., Xu, S., Montgomery, M. K., Kostas, S. A., Driver, S. E. and Mello, C. C. (1998). Potent and specific genetic interference by double-stranded RNA in Caenorhabditis elegans. Nature, 391, 806-11.

Foran, E., Bogush, A., Goffredo, M., Roncaglia, P., Gustincich, S., Pasinelli, P. and Trotti, D. (2011). Motor neuron impairment mediated by a sumoylated fragment of the glial glutamate transporter EAAT2. Glia.

Gidalevitz, T., Krupinski, T., Garcia, S. and Morimoto, R. I. (2009). Destabilizing protein polymorphisms in the genetic background direct phenotypic expression of mutant SOD1 toxicity. PLoS Genet, 5, e1000399.

Gingras, M., Beaulieu, M. M., Gagnon, V., Durham, H. D. and Berthod, F. (2008). In vitro study of axonal migration and myelination of motor neurons in a threedimensional tissue-engineered model. Glia, 56, 354-64.

Gingras, M., Champigny, M. F. and Berthod, F. (2007a). Differentiation of human adult skin-derived neuronal precursors into mature neurons. J Cell Physiol, 210, 498-506.

Gingras, M., Gagnon, V., Minotti, S., Durham, H. D. and Berthod, F. (2007b). Optimized protocols for isolation of primary motor neurons, astrocytes and microglia from embryonic mouse spinal cord. J Neurosci Methods, 163, 111-8.

Gitcho, M. A., Baloh, R. H., Chakraverty, S., Mayo, K., Norton, J. B., Levitch, D., Hatanpaa, K. J., White, C. L., 3rd, Bigio, E. H., Caselli, R., Baker, M., Al-Lozi, M. T., Morris, J. C., Pestronk, A., Rademakers, R., Goate, A. M. and Cairns, N. J. (2008). TDP-43 A315T mutation in familial motor neuron disease. Ann Neurol, 63, 535-8.

Gong, Y. H., Parsadanian, A. S., Andreeva, A., Snider, W. D. and Elliott, J. L. (2000). Restricted expression of G86R Cu/Zn superoxide dismutase in astrocytes results in astrocytosis but does not cause motoneuron degeneration. J Neurosci, 20, 660-5.

Gros-Louis, F., Andersen, P. M., Dupre, N., Urushitani, M., Dion, P., Souchon, F., D'Amour, M., Camu, W., Meininger, V., Bouchard, J. P., Rouleau, G. A. and Julien, J. P. (2009a). Chromogranin B P413L variant as risk factor and modifier of disease onset for amyotrophic lateral sclerosis. Proc Natl Acad Sci U S A. 
Gros-Louis, F., Gaspar, C. and Rouleau, G. A. (2006). Genetics of familial and sporadic amyotrophic lateral sclerosis. Biochim Biophys Acta, 1762, 956-72.

Gros-Louis, F., Gowing, G. and Julien, J. P. (2009b). Development of immunotherapeutic approaches to amyotrophic lateral sclerosis. Future Neurol, 4, 435-47.

Gros-Louis, F., Kriz, J., Kabashi, E., McDearmid, J., Millecamps, S., Urushitani, M., Lin, L., Dion, P., Zhu, Q., Drapeau, P., Julien, J. P. and Rouleau, G. A. (2008). Als2 mRNA splicing variants detected in $\mathrm{KO}$ mice rescue severe motor dysfunction phenotype in Als2 knock-down zebrafish. Hum Mol Genet, 17, 2691-702.

Gros-Louis, F., Meijer, I. A., Hand, C. K., Dube, M. P., MacGregor, D. L., Seni, M. H., Devon, R. S., Hayden, M. R., Andermann, F., Andermann, E. and Rouleau, G. A. (2003). An ALS2 gene mutation causes hereditary spastic paraplegia in a Pakistani kindred. Ann Neurol, 53, 144-5.

Gros-Louis, F., Soucy, G., Lariviere, R. and Julien, J. P. (2010). Intracerebroventricular infusion of monoclonal antibody or its derived Fab fragment against misfolded forms of SOD1 mutant delays mortality in a mouse model of ALS. J Neurochem, 113, 1188-99.

Gurney, M. E., Cutting, F. B., Zhai, P., Doble, A., Taylor, C. P., Andrus, P. K. and Hall, E. D. (1996). Benefit of vitamin E, riluzole, and gabapentin in a transgenic model of familial amyotrophic lateral sclerosis. Ann Neurol, 39, 147-57.

Gurney, M. E., Pu, H., Chiu, A. Y., Dal Canto, M. C., Polchow, C. Y., Alexander, D. D., Caliendo, J., Hentati, A., Kwon, Y. W., Deng, H. X. and et al. (1994). Motor neuron degeneration in mice that express a human $\mathrm{Cu}, \mathrm{Zn}$ superoxide dismutase mutation. Science, 264, 1772-5.

Hadano, S., Benn, S. C., Kakuta, S., Otomo, A., Sudo, K., Kunita, R., Suzuki-Utsunomiya, K., Mizumura, H., Shefner, J. M., Cox, G. A., Iwakura, Y., Brown, R. H., Jr. and Ikeda, J. E. (2006). Mice deficient in the Rab5 guanine nucleotide exchange factor ALS2/alsin exhibit age-dependent neurological deficits and altered endosome trafficking. Hum Mol Genet, 15, 233-50.

Hadano, S., Hand, C. K., Osuga, H., Yanagisawa, Y., Otomo, A., Devon, R. S., Miyamoto, N., Showguchi-Miyata, J., Okada, Y., Singaraja, R., Figlewicz, D. A., Kwiatkowski, T., Hosler, B. A., Sagie, T., Skaug, J., Nasir, J., Brown, R. H., Jr., Scherer, S. W., Rouleau, G. A., Hayden, M. R. and Ikeda, J. E. (2001). A gene encoding a putative GTPase regulator is mutated in familial amyotrophic lateral sclerosis 2. Nat Genet, 29, 16673.

Haffter, P., Granato, M., Brand, M., Mullins, M. C., Hammerschmidt, M., Kane, D. A., Odenthal, J., van Eeden, F. J., Jiang, Y. J., Heisenberg, C. P., Kelsh, R. N., FurutaniSeiki, M., Vogelsang, E., Beuchle, D., Schach, U., Fabian, C. and Nusslein-Volhard, C. (1996). The identification of genes with unique and essential functions in the development of the zebrafish, Danio rerio. Development, 123, 1-36.

Haidet-Phillips, A. M., Hester, M. E., Miranda, C. J., Meyer, K., Braun, L., Frakes, A., Song, S., Likhite, S., Murtha, M. J., Foust, K. D., Rao, M., Eagle, A., Kammesheidt, A., Christensen, A., Mendell, J. R., Burghes, A. H. and Kaspar, B. K. (2011). Astrocytes from familial and sporadic ALS patients are toxic to motor neurons. Nat Biotechnol.

Hanson, K. A., Kim, S. H., Wassarman, D. A. and Tibbetts, R. S. (2010). Ubiquilin modifies TDP-43 toxicity in a Drosophila model of amyotrophic lateral sclerosis (ALS). J Biol Chem, 285, 11068-72.

Hart, E. A., Caccamo, M., Harrow, J. L., Humphray, S. J., Gilbert, J. G., Trevanion, S., Hubbard, T., Rogers, J. and Rothschild, M. F. (2007). Lessons learned from the 
initial sequencing of the pig genome: comparative analysis of an $8 \mathrm{Mb}$ region of pig chromosome 17. Genome Biol, 8, R168.

Heiman-Patterson, T. D., Deitch, J. S., Blankenhorn, E. P., Erwin, K. L., Perreault, M. J., Alexander, B. K., Byers, N., Toman, I. and Alexander, G. M. (2005). Background and gender effects on survival in the TgN(SOD1-G93A)1Gur mouse model of ALS. J Neurol Sci, 236, 1-7.

Henion, P. D., Raible, D. W., Beattie, C. E., Stoesser, K. L., Weston, J. A. and Eisen, J. S. (1996). Screen for mutations affecting development of Zebrafish neural crest. Dev Genet, 18, 11-7.

Hester, M. E., Murtha, M. J., Song, S., Rao, M., Miranda, C. J., Meyer, K., Tian, J., Boulting, G., Schaffer, D. V., Zhu, M. X., Pfaff, S. L., Gage, F. H. and Kaspar, B. K. (2011). Rapid and Efficient Generation of Functional Motor Neurons From Human Pluripotent Stem Cells Using Gene Delivered Transcription Factor Codes. Mol Ther.

Howland, D. S., Liu, J., She, Y., Goad, B., Maragakis, N. J., Kim, B., Erickson, J., Kulik, J., DeVito, L., Psaltis, G., DeGennaro, L. J., Cleveland, D. W. and Rothstein, J. D. (2002). Focal loss of the glutamate transporter EAAT2 in a transgenic rat model of SOD1 mutant-mediated amyotrophic lateral sclerosis (ALS). Proc Natl Acad Sci U S A, 99, 1604-9.

$\mathrm{Hu}, \mathrm{B}$. Y. and Zhang, S. C. (2009). Differentiation of spinal motor neurons from pluripotent human stem cells. Nat Protoc, 4, 1295-304.

Hunter, D. D., Cashman, N., Morris-Valero, R., Bulock, J. W., Adams, S. P. and Sanes, J. R. (1991). An LRE (leucine-arginine-glutamate)-dependent mechanism for adhesion of neurons to S-laminin. J Neurosci, 11, 3960-71.

Hutton, M., Lendon, C. L., Rizzu, P., Baker, M., Froelich, S., Houlden, H., Pickering-Brown, S., Chakraverty, S., Isaacs, A., Grover, A., Hackett, J., Adamson, J., Lincoln, S., Dickson, D., Davies, P., Petersen, R. C., Stevens, M., de Graaff, E., Wauters, E., van Baren, J., Hillebrand, M., Joosse, M., Kwon, J. M., Nowotny, P., Che, L. K., Norton, J., Morris, J. C., Reed, L. A., Trojanowski, J., Basun, H., Lannfelt, L., Neystat, M., Fahn, S., Dark, F., Tannenberg, T., Dodd, P. R., Hayward, N., Kwok, J. B., Schofield, P. R., Andreadis, A., Snowden, J., Craufurd, D., Neary, D., Owen, F., Oostra, B. A., Hardy, J., Goate, A., van Swieten, J., Mann, D., Lynch, T. and Heutink, P. (1998). Association of missense and 5'-splice-site mutations in tau with the inherited dementia FTDP-17. Nature, 393, 702-5.

Johnson, J. O., Mandrioli, J., Benatar, M., Abramzon, Y., Van Deerlin, V. M., Trojanowski, J. Q., Gibbs, J. R., Brunetti, M., Gronka, S., Wuu, J., Ding, J., McCluskey, L., MartinezLage, M., Falcone, D., Hernandez, D. G., Arepalli, S., Chong, S., Schymick, J. C., Rothstein, J., Landi, F., Wang, Y. D., Calvo, A., Mora, G., Sabatelli, M., Monsurro, M. R., Battistini, S., Salvi, F., Spataro, R., Sola, P., Borghero, G., Galassi, G., Scholz, S. W., Taylor, J. P., Restagno, G., Chio, A. and Traynor, B. J. (2010). Exome sequencing reveals VCP mutations as a cause of familial ALS. Neuron, 68, 857-64.

Jonsson, P. A., Ernhill, K., Andersen, P. M., Bergemalm, D., Brannstrom, T., Gredal, O., Nilsson, P. and Marklund, S. L. (2004). Minute quantities of misfolded mutant superoxide dismutase-1 cause amyotrophic lateral sclerosis. Brain, 127, 73-88.

Jonsson, P. A., Graffmo, K. S., Andersen, P. M., Brannstrom, T., Lindberg, M., Oliveberg, M. and Marklund, S. L. (2006). Disulphide-reduced superoxide dismutase-1 in CNS of transgenic amyotrophic lateral sclerosis models. Brain, 129, 451-64.

Julien, J. P. and Kriz, J. (2006). Transgenic mouse models of amyotrophic lateral sclerosis. Biochim Biophys Acta, 1762, 1013-24. 
Kabashi, E., Bercier, V., Lissouba, A., Liao, M., Brustein, E., Rouleau, G. A. and Drapeau, P. (2011). FUS and TARDBP but Not SOD1 Interact in Genetic Models of Amyotrophic Lateral Sclerosis. PLoS Genet, 7, e1002214.

Kabashi, E., Lin, L., Tradewell, M. L., Dion, P. A., Bercier, V., Bourgouin, P., Rochefort, D., Bel Hadj, S., Durham, H. D., Vande Velde, C., Rouleau, G. A. and Drapeau, P. (2010). Gain and loss of function of ALS-related mutations of TARDBP (TDP-43) cause motor deficits in vivo. Hum Mol Genet, 19, 671-83.

Kabashi, E., Valdmanis, P. N., Dion, P., Spiegelman, D., McConkey, B. J., Vande Velde, C., Bouchard, J. P., Lacomblez, L., Pochigaeva, K., Salachas, F., Pradat, P. F., Camu, W., Meininger, V., Dupre, N. and Rouleau, G. A. (2008). TARDBP mutations in individuals with sporadic and familial amyotrophic lateral sclerosis. Nat Genet, 40, 572-4.

Kim, S. H., Shi, Y., Hanson, K. A., Williams, L. M., Sakasai, R., Bowler, M. J. and Tibbetts, R. S. (2009). Potentiation of amyotrophic lateral sclerosis (ALS)-associated TDP-43 aggregation by the proteasome-targeting factor, ubiquilin 1. J Biol Chem, 284, 808392.

Kosuge, Y., Sekikawa-Nishida, K., Negi, H., Ishige, K. and Ito, Y. (2009). Characterization of chronic glutamate-mediated motor neuron toxicity in organotypic spinal cord culture prepared from ALS model mice. Neurosci Lett, 454, 165-9.

Kraemer, B. C., Schuck, T., Wheeler, J. M., Robinson, L. C., Trojanowski, J. Q., Lee, V. M. and Schellenberg, G. D. (2010). Loss of murine TDP-43 disrupts motor function and plays an essential role in embryogenesis. Acta Neuropathol, 119, 409-19.

Kress, J. A., Kuhnlein, P., Winter, P., Ludolph, A. C., Kassubek, J., Muller, U. and Sperfeld, A. D. (2005). Novel mutation in the ALS2 gene in juvenile amyotrophic lateral sclerosis. Ann Neurol, 58, 800-3.

Kulshreshtha, D., Vijayalakshmi, K., Alladi, P. A., Sathyaprabha, T. N., Nalini, A. and Raju, T. R. (2011). Vascular endothelial growth factor attenuates neurodegenerative changes in the NSC-34 motor neuron cell line induced by cerebrospinal fluid of sporadic amyotrophic lateral sclerosis patients. Neurodegener Dis, 8, 322-30.

Kwiatkowski, T. J., Jr., Bosco, D. A., Leclerc, A. L., Tamrazian, E., Vanderburg, C. R., Russ, C., Davis, A., Gilchrist, J., Kasarskis, E. J., Munsat, T., Valdmanis, P., Rouleau, G. A., Hosler, B. A., Cortelli, P., de Jong, P. J., Yoshinaga, Y., Haines, J. L., Pericak-Vance, M. A., Yan, J., Ticozzi, N., Siddique, T., McKenna-Yasek, D., Sapp, P. C., Horvitz, H. R., Landers, J. E. and Brown, R. H., Jr. (2009). Mutations in the FUS/TLS gene on chromosome 16 cause familial amyotrophic lateral sclerosis. Science, 323, $1205-8$.

Lanson, N. A., Jr., Maltare, A., King, H., Smith, R., Kim, J. H., Taylor, J. P., Lloyd, T. E. and Pandey, U. B. (2011). A Drosophila model of FUS-related neurodegeneration reveals genetic interaction between FUS and TDP-43. Hum Mol Genet, 20, 2510-23.

Lariviere, R. C. and Julien, J. P. (2004). Functions of intermediate filaments in neuronal development and disease. J Neurobiol, 58, 131-48.

Lemmens, R., Van Hoecke, A., Hersmus, N., Geelen, V., D'Hollander, I., Thijs, V., Van Den Bosch, L., Carmeliet, P. and Robberecht, W. (2007). Overexpression of mutant superoxide dismutase 1 causes a motor axonopathy in the zebrafish. Hum Mol Genet, 16, 2359-65.

Li, Y., Ray, P., Rao, E. J., Shi, C., Guo, W., Chen, X., Woodruff, E. A., 3rd, Fushimi, K. and Wu, J. Y. (2010). A Drosophila model for TDP-43 proteinopathy. Proc Natl Acad Sci US A, 107, 3169-74. 
Liachko, N. F., Guthrie, C. R. and Kraemer, B. C. (2010). Phosphorylation promotes neurotoxicity in a Caenorhabditis elegans model of TDP-43 proteinopathy. J Neurosci, 30, 16208-19.

Lin, M. J., Cheng, C. W. and Shen, C. K. (2011). Neuronal function and dysfunction of Drosophila dTDP. PLoS One, 6, e20371.

Lindblad-Toh, K., Wade, C. M., Mikkelsen, T. S., Karlsson, E. K., Jaffe, D. B., Kamal, M., Clamp, M., Chang, J. L., Kulbokas, E. J., 3rd, Zody, M. C., Mauceli, E., Xie, X., Breen, M., Wayne, R. K., Ostrander, E. A., Ponting, C. P., Galibert, F., Smith, D. R., DeJong, P. J., Kirkness, E., Alvarez, P., Biagi, T., Brockman, W., Butler, J., Chin, C. W., Cook, A., Cuff, J., Daly, M. J., DeCaprio, D., Gnerre, S., Grabherr, M., Kellis, M., Kleber, M., Bardeleben, C., Goodstadt, L., Heger, A., Hitte, C., Kim, L., Koepfli, K. P., Parker, H. G., Pollinger, J. P., Searle, S. M., Sutter, N. B., Thomas, R., Webber, C., Baldwin, J., Abebe, A., Abouelleil, A., Aftuck, L., Ait-Zahra, M., Aldredge, T., Allen, N., An, P., Anderson, S., Antoine, C., Arachchi, H., Aslam, A., Ayotte, L., Bachantsang, P., Barry, A., Bayul, T., Benamara, M., Berlin, A., Bessette, D., Blitshteyn, B., Bloom, T., Blye, J., Boguslavskiy, L., Bonnet, C., Boukhgalter, B., Brown, A., Cahill, P., Calixte, N., Camarata, J., Cheshatsang, Y., Chu, J., Citroen, M., Collymore, A., Cooke, P., Dawoe, T., Daza, R., Decktor, K., DeGray, S., Dhargay, N., Dooley, K., Dorje, P., Dorjee, K., Dorris, L., Duffey, N., Dupes, A., Egbiremolen, O., Elong, R., Falk, J., Farina, A., Faro, S., Ferguson, D., Ferreira, P., Fisher, S., FitzGerald, M., Foley, K., Foley, C., Franke, A., Friedrich, D., Gage, D., Garber, M., Gearin, G., Giannoukos, G., Goode, T., Goyette, A., Graham, J., Grandbois, E., Gyaltsen, K., Hafez, N., Hagopian, D., Hagos, B., Hall, J., Healy, C., Hegarty, R., Honan, T., Horn, A., Houde, N., Hughes, L., Hunnicutt, L., Husby, M., Jester, B., Jones, C., Kamat, A., Kanga, B., Kells, C., Khazanovich, D., Kieu, A. C., Kisner, P., Kumar, M., Lance, K., Landers, T., Lara, M., Lee, W., Leger, J. P., Lennon, N., Leuper, L., LeVine, S., Liu, J., Liu, X., Lokyitsang, Y., Lokyitsang, T., Lui, A., Macdonald, J., Major, J., Marabella, R., Maru, K., Matthews, C., McDonough, S., Mehta, T., Meldrim, J., Melnikov, A., Meneus, L., Mihalev, A., Mihova, T., Miller, K., Mittelman, R., Mlenga, V., Mulrain, L., Munson, G., Navidi, A., Naylor, J., Nguyen, T., Nguyen, N., Nguyen, C., Nicol, R., Norbu, N., Norbu, C., Novod, N., Nyima, T., Olandt, P., O'Neill, B., O'Neill, K., Osman, S., Oyono, L., Patti, C., Perrin, D., Phunkhang, P., Pierre, F., Priest, M., Rachupka, A., Raghuraman, S., Rameau, R., Ray, V., Raymond, C., Rege, F., Rise, C., Rogers, J., Rogov, P., Sahalie, J., Settipalli, S., Sharpe, T., Shea, T., Sheehan, M., Sherpa, N., Shi, J., Shih, D., Sloan, J., Smith, C., Sparrow, T., Stalker, J., Stange-Thomann, N., Stavropoulos, S., Stone, C., Stone, S., Sykes, S., Tchuinga, P., Tenzing, P., Tesfaye, S., Thoulutsang, D., Thoulutsang, Y., Topham, K., Topping, I., Tsamla, T., Vassiliev, H., Venkataraman, V., Vo, A., Wangchuk, T., Wangdi, T., Weiand, M., Wilkinson, J., Wilson, A., Yadav, S., Yang, S., Yang, X., Young, G., Yu, Q., Zainoun, J., Zembek, L., Zimmer, A. and Lander, E. S. (2005). Genome sequence, comparative analysis and haplotype structure of the domestic dog. Nature, 438, 803-19.

Lu, Y., Ferris, J. and Gao, F. B. (2009). Frontotemporal dementia and amyotrophic lateral sclerosis-associated disease protein TDP-43 promotes dendritic branching. Mol Brain, 2, 30.

Lunn, J. S., Sakowski, S. A., Kim, B., Rosenberg, A. A. and Feldman, E. L. (2009). Vascular endothelial growth factor prevents G93A-SOD1-induced motor neuron degeneration. Dev Neurobiol, 69, 871-84. 
Lynch, T., Sano, M., Marder, K. S., Bell, K. L., Foster, N. L., Defendini, R. F., Sima, A. A., Keohane, C., Nygaard, T. G., Fahn, S. and et al. (1994). Clinical characteristics of a family with chromosome 17-linked disinhibition-dementia-parkinsonismamyotrophy complex. Neurology, 44, 1878-84.

Maeda, I., Kohara, Y., Yamamoto, M. and Sugimoto, A. (2001). Large-scale analysis of gene function in Caenorhabditis elegans by high-throughput RNAi. Curr Biol, 11, 171-6.

Maruyama, H., Morino, H., Ito, H., Izumi, Y., Kato, H., Watanabe, Y., Kinoshita, Y., Kamada, M., Nodera, H., Suzuki, H., Komure, O., Matsuura, S., Kobatake, K., Morimoto, N., Abe, K., Suzuki, N., Aoki, M., Kawata, A., Hirai, T., Kato, T., Ogasawara, K., Hirano, A., Takumi, T., Kusaka, H., Hagiwara, K., Kaji, R. and Kawakami, H. (2010). Mutations of optineurin in amyotrophic lateral sclerosis. Nature, 465, 223-6.

Mazzone, G. L. and Nistri, A. (2011). Electrochemical detection of endogenous glutamate release from rat spinal cord organotypic slices as a real-time method to monitor excitotoxicity. J Neurosci Methods, 197, 128-32.

McIntire, S. L., Jorgensen, E. and Horvitz, H. R. (1993). Genes required for GABA function in Caenorhabditis elegans. Nature, 364, 334-7.

Miguel, L., Frebourg, T., Campion, D. and Lecourtois, M. (2011). Both cytoplasmic and nuclear accumulations of the protein are neurotoxic in Drosophila models of TDP43 proteinopathies. Neurobiol Dis, 41, 398-406.

Millecamps, S., Robertson, J., Lariviere, R., Mallet, J. and Julien, J. P. (2006). Defective axonal transport of neurofilament proteins in neurons overexpressing peripherin. $J$ Neurochem, 98, 926-38.

Millecamps, S., Salachas, F., Cazeneuve, C., Gordon, P., Bricka, B., Camuzat, A., GuillotNoel, L., Russaouen, O., Bruneteau, G., Pradat, P. F., Le Forestier, N., Vandenberghe, N., Danel-Brunaud, V., Guy, N., Thauvin-Robinet, C., Lacomblez, L., Couratier, P., Hannequin, D., Seilhean, D., Le Ber, I., Corcia, P., Camu, W., Brice, A., Rouleau, G., LeGuern, E. and Meininger, V. (2010). SOD1, ANG, VAPB, TARDBP, and FUS mutations in familial amyotrophic lateral sclerosis: genotypephenotype correlations. J Med Genet, 47, 554-60.

Mitchell, J., Paul, P., Chen, H. J., Morris, A., Payling, M., Falchi, M., Habgood, J., Panoutsou, S., Winkler, S., Tisato, V., Hajitou, A., Smith, B., Vance, C., Shaw, C., Mazarakis, N. D. and de Belleroche, J. (2010). Familial amyotrophic lateral sclerosis is associated with a mutation in D-amino acid oxidase. Proc Natl Acad Sci U S A, 107, 7556-61.

Mitne-Neto, M., Machado-Costa, M., Marchetto, M. C., Bengtson, M. H., Joazeiro, C. A., Tsuda, H., Bellen, H. J., Silva, H. C., Oliveira, A. S., Lazar, M., Muotri, A. R. and Zatz, M. (2011). Downregulation of VAPB expression in motor neurons derived from induced pluripotent stem cells of ALS8 patients. Hum Mol Genet.

Mockett, R. J., Radyuk, S. N., Benes, J. J., Orr, W. C. and Sohal, R. S. (2003). Phenotypic effects of familial amyotrophic lateral sclerosis mutant Sod alleles in transgenic Drosophila. Proc Natl Acad Sci U S A, 100, 301-6.

Mulder, D. W. (1982). Clinical limits of amyotrophic lateral sclerosis. Adv Neurol, 36, 15-22.

Nagai, M., Aoki, M., Miyoshi, I., Kato, M., Pasinelli, P., Kasai, N., Brown, R. H., Jr. and Itoyama, Y. (2001). Rats expressing human cytosolic copper-zinc superoxide dismutase transgenes with amyotrophic lateral sclerosis: associated mutations develop motor neuron disease. J Neurosci, 21, 9246-54.

Nasevicius, A. and Ekker, S. C. (2000). Effective targeted gene 'knockdown' in zebrafish. Nat Genet, 26, 216-20. 
Oeda, T., Shimohama, S., Kitagawa, N., Kohno, R., Imura, T., Shibasaki, H. and Ishii, N. (2001). Oxidative stress causes abnormal accumulation of familial amyotrophic lateral sclerosis-related mutant SOD1 in transgenic Caenorhabditis elegans. Hum Mol Genet, 10, 2013-23.

Park, K. S., Kim, H. J., Choi, W. J., Kim, M. and Lee, K. W. (2004). Detection method of the adjacent motor neuronal death in an in vitro co-culture model of familial ALSassociated $\mathrm{Cu} / \mathrm{Zn}$ superoxide dismutase. Biotechnol Lett, 26, 1201-5.

Parkes, T. L., Elia, A. J., Dickinson, D., Hilliker, A. J., Phillips, J. P. and Boulianne, G. L. (1998). Extension of Drosophila lifespan by overexpression of human SOD1 in motorneurons. Nat Genet, 19, 171-4.

Pasinelli, P., Belford, M. E., Lennon, N., Bacskai, B. J., Hyman, B. T., Trotti, D. and Brown, R. H., Jr. (2004). Amyotrophic lateral sclerosis-associated SOD1 mutant proteins bind and aggregate with Bcl-2 in spinal cord mitochondria. Neuron, 43, 19-30.

Phillips, J. P., Campbell, S. D., Michaud, D., Charbonneau, M. and Hilliker, A. J. (1989). Null mutation of copper/zinc superoxide dismutase in Drosophila confers hypersensitivity to paraquat and reduced longevity. Proc Natl Acad Sci U S A, 86, 2761-5.

Pramatarova, A., Laganiere, J., Roussel, J., Brisebois, K. and Rouleau, G. A. (2001). Neuronspecific expression of mutant superoxide dismutase 1 in transgenic mice does not lead to motor impairment. J Neurosci, 21, 3369-74.

Ramesh, T., Lyon, A. N., Pineda, R. H., Wang, C., Janssen, P. M., Canan, B. D., Burghes, A. H. and Beattie, C. E. (2010). A genetic model of amyotrophic lateral sclerosis in zebrafish displays phenotypic hallmarks of motoneuron disease. Dis Model Mech, 3, 652-62.

Reaume, A. G., Elliott, J. L., Hoffman, E. K., Kowall, N. W., Ferrante, R. J., Siwek, D. F., Wilcox, H. M., Flood, D. G., Beal, M. F., Brown, R. H., Jr., Scott, R. W. and Snider, W. D. (1996). Motor neurons in $\mathrm{Cu} / \mathrm{Zn}$ superoxide dismutase-deficient mice develop normally but exhibit enhanced cell death after axonal injury. Nat Genet, 13, 43-7.

Renton, A. E., Majounie, E., Waite, A., Simon-Sanchez, J., Rollinson, S., Gibbs, J. R., Schymick, J. C., Laaksovirta, H., van Swieten, J. C., Myllykangas, L., Kalimo, H., Paetau, A., Abramzon, Y., Remes, A. M., Kaganovich, A., Scholz, S. W., Duckworth, J., Ding, J., Harmer, D. W., Hernandez, D. G., Johnson, J. O., Mok, K., Ryten, M., Trabzuni, D., Guerreiro, R. J., Orrell, R. W., Neal, J., Murray, A., Pearson, J., Jansen, I. E., Sondervan, D., Seelaar, H., Blake, D., Young, K., Halliwell, N., Callister, J. B., Toulson, G., Richardson, A., Gerhard, A., Snowden, J., Mann, D., Neary, D., Nalls, M. A., Peuralinna, T., Jansson, L., Isoviita, V., Kaivorinne, A., Holtta-Vuori, M., Ikonen, E., Sulkava, R., Benatar, M., Wuu, J., Chio, A., Restagno, G., Borghero, G., Sabatelli, M., Consortium, T. I., Heckerman, D., Rogaeva, E., Zinman, L., Rothstein, J. D., Sendtner, M., Drepper, C., Eichler, E. E., Alkan, C., Abdullaev, Z., Pack, S. D., Dutra, A., Pak, E., Hardy, J., Singleton, A., Williams, N. M., Heutink, P., PickeringBrown, S., Morris, H. R., P.J., T. and Traynor, B. J. (2011). A Hexanucleotide Repeat Expansion in C9ORF72 Is the Cause of Chromosome 9p21-Linked ALS-FTD. Neuron.

Ripps, M. E., Huntley, G. W., Hof, P. R., Morrison, J. H. and Gordon, J. W. (1995). Transgenic mice expressing an altered murine superoxide dismutase gene provide an animal model of amyotrophic lateral sclerosis. Proc Natl Acad Sci U S A, 92, 68993. 
Ritson, G. P., Custer, S. K., Freibaum, B. D., Guinto, J. B., Geffel, D., Moore, J., Tang, W., Winton, M. J., Neumann, M., Trojanowski, J. Q., Lee, V. M., Forman, M. S. and Taylor, J. P. (2010). TDP-43 mediates degeneration in a novel Drosophila model of disease caused by mutations in VCP/p97. J Neurosci, 30, 7729-39.

Rosen, D. R., Siddique, T., Patterson, D., Figlewicz, D. A., Sapp, P., Hentati, A., Donaldson, D., Goto, J., O'Regan, J. P., Deng, H. X. and et al. (1993). Mutations in Cu/Zn superoxide dismutase gene are associated with familial amyotrophic lateral sclerosis. Nature, 362, 59-62.

Sanelli, T., Ge, W., Leystra-Lantz, C. and Strong, M. J. (2007). Calcium mediated excitotoxicity in neurofilament aggregate-bearing neurons in vitro is NMDA receptor dependant. J Neurol Sci, 256, 39-51.

Sauer, B. (1998). Inducible gene targeting in mice using the Cre/lox system. Methods, 14, 38192.

Saxena, S., Cabuy, E. and Caroni, P. (2006). A role for motoneuron subtype-selective ER stress in disease manifestations of FALS mice. Nat Neurosci, 12, 627-36.

Schnaar, R. I. and Schaffner, A. E. (1981). Separation of cell types from embryonic chicken and rat spinal cord: characterization of motoneuron-enriched fractions. J Neurosci, 1, 204-17.

Sephton, C. F., Good, S. K., Atkin, S., Dewey, C. M., Mayer, P., 3rd, Herz, J. and Yu, G. (2010). TDP-43 is a developmentally regulated protein essential for early embryonic development. J Biol Chem, 285, 6826-34.

Simpson, C. L., Lemmens, R., Miskiewicz, K., Broom, W. J., Hansen, V. K., van Vught, P. W., Landers, J. E., Sapp, P., Van Den Bosch, L., Knight, J., Neale, B. M., Turner, M. R., Veldink, J. H., Ophoff, R. A., Tripathi, V. B., Beleza, A., Shah, M. N., Proitsi, P., Van Hoecke, A., Carmeliet, P., Horvitz, H. R., Leigh, P. N., Shaw, C. E., van den Berg, L. H., Sham, P. C., Powell, J. F., Verstreken, P., Brown, R. H., Jr., Robberecht, W. and Al-Chalabi, A. (2009). Variants of the elongator protein 3 (ELP3) gene are associated with motor neuron degeneration. Hum Mol Genet, 18, 472-81.

Solnica-Krezel, L., Stemple, D. L., Mountcastle-Shah, E., Rangini, Z., Neuhauss, S. C., Malicki, J., Schier, A. F., Stainier, D. Y., Zwartkruis, F., Abdelilah, S. and Driever, W. (1996). Mutations affecting cell fates and cellular rearrangements during gastrulation in zebrafish. Development, 123, 67-80.

Sreedharan, J., Blair, I. P., Tripathi, V. B., Hu, X., Vance, C., Rogelj, B., Ackerley, S., Durnall, J. C., Williams, K. L., Buratti, E., Baralle, F., de Belleroche, J., Mitchell, J. D., Leigh, P. N., Al-Chalabi, A., Miller, C. C., Nicholson, G. and Shaw, C. E. (2008). TDP-43 mutations in familial and sporadic amyotrophic lateral sclerosis. Science, 319, 166872.

Stabenfeldt, S. E., Munglani, G., Garcia, A. J. and LaPlaca, M. C. (2010). Biomimetic microenvironment modulates neural stem cell survival, migration, and differentiation. Tissue Eng Part A, 16, 3747-58.

Stallings, N. R., Puttaparthi, K., Luther, C. M., Burns, D. K. and Elliott, J. L. (2010). Progressive motor weakness in transgenic mice expressing human TDP-43. Neurobiol Dis, 40, 404-14.

Strong, M. J. and Yang, W. (2011). The Frontotemporal Syndromes of ALS. Clinicopathological Correlates. J Mol Neurosci.

Sulston, J. E. (1983). Neuronal cell lineages in the nematode Caenorhabditis elegans. Cold Spring Harb Symp Quant Biol, 48 Pt 2, 443-52. 
Sulston, J. E., Schierenberg, E., White, J. G. and Thomson, J. N. (1983). The embryonic cell lineage of the nematode Caenorhabditis elegans. Dev Biol, 100, 64-119.

Swarup, V., Phaneuf, D., Bareil, C., Robertson, J., Rouleau, G. A., Kriz, J. and Julien, J. P. (2011). Pathological hallmarks of amyotrophic lateral sclerosis/frontotemporal lobar degeneration in transgenic mice produced with TDP-43 genomic fragments. Brain, 134, 2610-26.

Tabata, R. C., Wilson, J. M., Ly, P., Zwiegers, P., Kwok, D., Van Kampen, J. M., Cashman, N. and Shaw, C. A. (2008). Chronic exposure to dietary sterol glucosides is neurotoxic to motor neurons and induces an ALS-PDC phenotype. Neuromolecular Med, 10, 2439.

Takahashi, K., Okita, K., Nakagawa, M. and Yamanaka, S. (2007a). Induction of pluripotent stem cells from fibroblast cultures. Nat Protoc, 2, 3081-9.

Takahashi, K., Tanabe, K., Ohnuki, M., Narita, M., Ichisaka, T., Tomoda, K. and Yamanaka, S. (2007b). Induction of pluripotent stem cells from adult human fibroblasts by defined factors. Cell, 131, 861-72.

Tandan, R. and Bradley, W. G. (1985). Amyotrophic lateral sclerosis: Part 1. Clinical features, pathology, and ethical issues in management. Ann Neurol, 18, 271-80.

Texido, L., Hernandez, S., Martin-Satue, M., Povedano, M., Casanovas, A., Esquerda, J., Marsal, J. and Solsona, C. (2011). Sera from amyotrophic lateral sclerosis patients induce the non-canonical activation of NMDA receptors "in vitro". Neurochem Int, doi:10.1016/j.neuint.2011.07.006.

Toma, J. G., Akhavan, M., Fernandes, K. J., Barnabe-Heider, F., Sadikot, A., Kaplan, D. R. and Miller, F. D. (2001). Isolation of multipotent adult stem cells from the dermis of mammalian skin. Nat Cell Biol, 3, 778-84.

Tovar, Y. R. L. B., Santa-Cruz, L. D. and Tapia, R. (2009). Experimental models for the study of neurodegeneration in amyotrophic lateral sclerosis. Mol Neurodegener, 4, 31.

Tradewell, M. L., Cooper, L. A., Minotti, S. and Durham, H. D. (2011). Calcium dysregulation, mitochondrial pathology and protein aggregation in a culture model of amyotrophic lateral sclerosis: mechanistic relationship and differential sensitivity to intervention. Neurobiol Dis, 42, 265-75.

Tradewell, M. L. and Durham, H. D. (2010). Calpastatin reduces toxicity of SOD1G93A in a culture model of amyotrophic lateral sclerosis. Neuroreport, 21, 976-9.

Trotti, D., Aoki, M., Pasinelli, P., Berger, U. V., Danbolt, N. C., Brown, R. H., Jr. and Hediger, M. A. (2001). Amyotrophic lateral sclerosis-linked glutamate transporter mutant has impaired glutamate clearance capacity. J Biol Chem, 276, 576-82.

Trotti, D., Rolfs, A., Danbolt, N. C., Brown, R. H., Jr. and Hediger, M. A. (1999). SOD1 mutants linked to amyotrophic lateral sclerosis selectively inactivate a glial glutamate transporter. Nat Neurosci, 2, 427-33.

Tscherter, A., Heuschkel, M. O., Renaud, P. and Streit, J. (2001). Spatiotemporal characterization of rhythmic activity in rat spinal cord slice cultures. Eur J Neurosci, 14, 179-90.

Tu, P. H., Raju, P., Robinson, K. A., Gurney, M. E., Trojanowski, J. Q. and Lee, V. M. (1996). Transgenic mice carrying a human mutant superoxide dismutase transgene develop neuronal cytoskeletal pathology resembling human amyotrophic lateral sclerosis lesions. Proc Natl Acad Sci U S A, 93, 3155-60.

Turner, B. J., Atkin, J. D., Farg, M. A., Zang, D. W., Rembach, A., Lopes, E. C., Patch, J. D., Hill, A. F. and Cheema, S. S. (2005). Impaired extracellular secretion of mutant superoxide dismutase 1 associates with neurotoxicity in familial amyotrophic lateral sclerosis. J Neurosci, 25, 108-17. 
Urushitani, M., Ezzi, S. A., Matsuo, A., Tooyama, I. and Julien, J. P. (2008). The endoplasmic reticulum-Golgi pathway is a target for translocation and aggregation of mutant superoxide dismutase linked to ALS. Faseb J, 22, 2476-87.

Urushitani, M., Kurisu, J., Tsukita, K. and Takahashi, R. (2002). Proteasomal inhibition by misfolded mutant superoxide dismutase 1 induces selective motor neuron death in familial amyotrophic lateral sclerosis. J Neurochem, 83, 1030-42.

Urushitani, M., Sik, A., Sakurai, T., Nukina, N., Takahashi, R. and Julien, J. P. (2006). Chromogranin-mediated secretion of mutant superoxide dismutase proteins linked to amyotrophic lateral sclerosis. Nat Neurosci, 9, 108-18.

Van Deerlin, V. M., Leverenz, J. B., Bekris, L. M., Bird, T. D., Yuan, W., Elman, L. B., Clay, D., Wood, E. M., Chen-Plotkin, A. S., Martinez-Lage, M., Steinbart, E., McCluskey, L., Grossman, M., Neumann, M., Wu, I. L., Yang, W. S., Kalb, R., Galasko, D. R., Montine, T. J., Trojanowski, J. Q., Lee, V. M., Schellenberg, G. D. and Yu, C. E. (2008). TARDBP mutations in amyotrophic lateral sclerosis with TDP-43 neuropathology: a genetic and histopathological analysis. Lancet Neurol, 7, 409-16.

Vance, C., Rogelj, B., Hortobagyi, T., De Vos, K. J., Nishimura, A. L., Sreedharan, J., Hu, X., Smith, B., Ruddy, D., Wright, P., Ganesalingam, J., Williams, K. L., Tripathi, V., Al-Saraj, S., AlChalabi, A., Leigh, P. N., Blair, I. P., Nicholson, G., de Belleroche, J., Gallo, J. M., Miller, C. C. and Shaw, C. E. (2009). Mutations in FUS, an RNA processing protein, cause familial amyotrophic lateral sclerosis type 6. Science, 323, 1208-11.

Vijayalakshmi, K., Alladi, P. A., Ghosh, S., Prasanna, V. K., Sagar, B. C., Nalini, A., Sathyaprabha, T. N. and Raju, T. R. (2011). Evidence of endoplasmic reticular stress in the spinal motor neurons exposed to CSF from sporadic amyotrophic lateral sclerosis patients. Neurobiol Dis, 41, 695-705.

Vijayalakshmi, K., Alladi, P. A., Sathyaprabha, T. N., Subramaniam, J. R., Nalini, A. and Raju, T. R. (2009). Cerebrospinal fluid from sporadic amyotrophic lateral sclerosis patients induces degeneration of a cultured motor neuron cell line. Brain Res, 1263, 122-33.

Voigt, A., Herholz, D., Fiesel, F. C., Kaur, K., Muller, D., Karsten, P., Weber, S. S., Kahle, P. J., Marquardt, T. and Schulz, J. B. (2010). TDP-43-mediated neuron loss in vivo requires RNA-binding activity. PLoS One, 5, e12247.

Walker, L. M., Huber, M., Doores, K. J., Falkowska, E., Pejchal, R., Julien, J. P., Wang, S. K., Ramos, A., Chan-Hui, P. Y., Moyle, M., Mitcham, J. L., Hammond, P. W., Olsen, O. A., Phung, P., Fling, S., Wong, C. H., Phogat, S., Wrin, T., Simek, M. D., Principal Investigators, P. G., Koff, W. C., Wilson, I. A., Burton, D. R. and Poignard, P. (2011). Broad neutralization coverage of HIV by multiple highly potent antibodies. Nature, 477, 466-70.

Wang, J., Farr, G. W., Hall, D. H., Li, F., Furtak, K., Dreier, L. and Horwich, A. L. (2009a). An ALS-linked mutant SOD1 produces a locomotor defect associated with aggregation and synaptic dysfunction when expressed in neurons of Caenorhabditis elegans. PLoS Genet, 5, e1000350.

Wang, J., Slunt, H., Gonzales, V., Fromholt, D., Coonfield, M., Copeland, N. G., Jenkins, N. A. and Borchelt, D. R. (2003). Copper-binding-site-null SOD1 causes ALS in transgenic mice: aggregates of non-native SOD1 delineate a common feature. Hum Mol Genet, 12, 2753-64.

Wang, L., Deng, H. X., Grisotti, G., Zhai, H., Siddique, T. and Roos, R. P. (2009b). Wild-type SOD1 overexpression accelerates disease onset of a G85R SOD1 mouse. Hum Mol Genet, 18, 1642-51. 
Wang, L. J., Lu, Y. Y., Muramatsu, S., Ikeguchi, K., Fujimoto, K., Okada, T., Mizukami, H., Matsushita, T., Hanazono, Y., Kume, A., Nagatsu, T., Ozawa, K. and Nakano, I. (2002). Neuroprotective effects of glial cell line-derived neurotrophic factor mediated by an adeno-associated virus vector in a transgenic animal model of amyotrophic lateral sclerosis. J Neurosci, 22, 6920-8.

Watson, M. R., Lagow, R. D., Xu, K., Zhang, B. and Bonini, N. M. (2008). A drosophila model for amyotrophic lateral sclerosis reveals motor neuron damage by human SOD1. J Biol Chem, 283, 24972-81.

Wegorzewska, I., Bell, S., Cairns, N. J., Miller, T. M. and Baloh, R. H. (2009). TDP-43 mutant transgenic mice develop features of ALS and frontotemporal lobar degeneration. Proc Natl Acad Sci U S A, 106, 18809-14.

White, J., Southgate, E., Thomson, J. and Brenner, S. (1986). The structure of the nervous system of the nematode Caenorhabditis elegans. Philos Trans R Soc Lond Biol, 314, 1-340.

Wichterle, H., Lieberam, I., Porter, J. A. and Jessell, T. M. (2002). Directed differentiation of embryonic stem cells into motor neurons. Cell, 110, 385-97.

Wils, H., Kleinberger, G., Janssens, J., Pereson, S., Joris, G., Cuijt, I., Smits, V., Ceuterick-de Groote, C., Van Broeckhoven, C. and Kumar-Singh, S. (2010). TDP-43 transgenic mice develop spastic paralysis and neuronal inclusions characteristic of ALS and frontotemporal lobar degeneration. Proc Natl Acad Sci U S A, 107, 3858-63.

Wong, P. C., Pardo, C. A., Borchelt, D. R., Lee, M. K., Copeland, N. G., Jenkins, N. A., Sisodia, S. S., Cleveland, D. W. and Price, D. L. (1995). An adverse property of a familial ALS-linked SOD1 mutation causes motor neuron disease characterized by vacuolar degeneration of mitochondria. Neuron, 14, 1105-16.

Wu, L. S., Cheng, W. C., Hou, S. C., Yan, Y. T., Jiang, S. T. and Shen, C. K. (2010). TDP-43, a neuro-pathosignature factor, is essential for early mouse embryogenesis. Genesis, $48,56-62$.

Xu, Y. F., Gendron, T. F., Zhang, Y. J., Lin, W. L., D'Alton, S., Sheng, H., Casey, M. C., Tong, J., Knight, J., Yu, X., Rademakers, R., Boylan, K., Hutton, M., McGowan, E., Dickson, D. W., Lewis, J. and Petrucelli, L. (2010). Wild-type human TDP-43 expression causes TDP-43 phosphorylation, mitochondrial aggregation, motor deficits, and early mortality in transgenic mice. J Neurosci, 30, 10851-9.

Yamanaka, K., Miller, T. M., McAlonis-Downes, M., Chun, S. J. and Cleveland, D. W. (2006). Progressive spinal axonal degeneration and slowness in ALS2-deficient mice. Ann Neurol, 60, 95-104.

Yang, C., Tan, W., Whittle, C., Qiu, L., Cao, L., Akbarian, S. and Xu, Z. (2010). The Cterminal TDP-43 fragments have a high aggregation propensity and harm neurons by a dominant-negative mechanism. PLoS One, 5, e15878.

Yang, Y., Hentati, A., Deng, H. X., Dabbagh, O., Sasaki, T., Hirano, M., Hung, W. Y., Ouahchi, K., Yan, J., Azim, A. C., Cole, N., Gascon, G., Yagmour, A., Ben-Hamida, M., Pericak-Vance, M., Hentati, F. and Siddique, T. (2001). The gene encoding alsin, a protein with three guanine-nucleotide exchange factor domains, is mutated in a form of recessive amyotrophic lateral sclerosis. Nat Genet, 29, 160-5.

Young, K. C., McGehee, D. S. and Brorson, J. R. (2007). Glutamate receptor expression and chronic glutamate toxicity in rat motor cortex. Neurobiol Dis, 26, 78-85.

Zhou, H., Huang, C., Chen, H., Wang, D., Landel, C. P., Xia, P. Y., Bowser, R., Liu, Y. J. and Xia, X. G. (2010). Transgenic rat model of neurodegeneration caused by mutation in the TDP gene. PLoS Genet, 6, e1000887. 
AMYOTROPHIC

LATERAL SCLEROSIS

Eaced by Marton H. maver

\section{Amyotrophic Lateral Sclerosis}

Edited by Prof. Martin Maurer
ISBN 978-953-307-806-9

Hard cover, 718 pages

Publisher InTech

Published online 20, January, 2012

Published in print edition January, 2012

Though considerable amount of research, both pre-clinical and clinical, has been conducted during recent years, Amyotrophic Lateral Sclerosis (ALS) remains one of the mysterious diseases of the 21st century. Great efforts have been made to develop pathophysiological models and to clarify the underlying pathology, and with novel instruments in genetics and transgenic techniques, the aim for finding a durable cure comes into scope. On the other hand, most pharmacological trials failed to show a benefit for ALS patients. In this book, the reader will find a compilation of state-of-the-art reviews about the etiology, epidemiology, and pathophysiology of ALS, the molecular basis of disease progression and clinical manifestations, the genetics familial ALS, as well as novel diagnostic criteria in the field of electrophysiology. An overview over all relevant pharmacological trials in ALS patients is also included, while the book concludes with a discussion on current advances and future trends in ALS research.

\section{How to reference}

In order to correctly reference this scholarly work, feel free to copy and paste the following:

François Berthod and François Gros-Louis (2012). In Vivo and In Vitro Models to Study Amyotrophic Lateral Sclerosis, Amyotrophic Lateral Sclerosis, Prof. Martin Maurer (Ed.), ISBN: 978-953-307-806-9, InTech, Available from: http://www.intechopen.com/books/amyotrophic-lateral-sclerosis/in-vivo-and-in-vitro-models-tostudy-amyotrophic-lateral-sclerosis

\section{INTECH}

open science | open minds

\section{InTech Europe}

University Campus STeP Ri

Slavka Krautzeka 83/A

51000 Rijeka, Croatia

Phone: +385 (51) 770447

Fax: +385 (51) 686166

www.intechopen.com

\section{InTech China}

Unit 405, Office Block, Hotel Equatorial Shanghai

No.65, Yan An Road (West), Shanghai, 200040, China

中国上海市延安西路65号上海国际贵都大饭店办公楼 405 单元

Phone: +86-21-62489820

Fax: $+86-21-62489821$ 
(C) 2012 The Author(s). Licensee IntechOpen. This is an open access article distributed under the terms of the Creative Commons Attribution 3.0 License, which permits unrestricted use, distribution, and reproduction in any medium, provided the original work is properly cited. 